Steep-Slope Assembly Testing of Clay and Concrete Tile with and without Cool Pigmented Colors

William A. Miller, Ph.D.

Buildings Technology Center

Oak Ridge National Laboratory

Hashem Akbari, Principal Investigator
Heat Island Group
Lawrence Berkeley National Laboratory

Date Published: November 2005

Prepared by the

OAK RIDGE NATIONAL LABORATORY

Oak Ridge, Tennessee 37831-6283

managed by

UT-BATTELLE, LLC

for the

U.S. DEPARTMENT OF ENERGY

under contract DE-AC05-00OR22725 


\section{DOCUMENT AVAILABILITY}

Reports produced after January 1, 1996, are generally available free via the U.S. Department of Energy (DOE) Information Bridge:

Web site: http://www.osti.gov/bridge

Reports produced before January 1, 1996, may be purchased by members of the public from the following source:

National Technical Information Service

5285 Port Royal Road

Springfield, VA 22161

Telephone: 703-605-6000 (1-800-553-6847)

TDD: 703-487-4639

Fax: 703-605-6900

E-mail: info@ntis.fedworld.gov

Web site: http://www.ntis.gov/support/ordernowabout.htm

Reports are available to DOE employees, DOE contractors, Energy Technology Data Exchange (ETDE) representatives, and International Nuclear Information System (INIS) representatives from the following source:

Office of Scientific and Technical Information

P.O. Box 62

Oak Ridge, TN 37831

Telephone: 865-576-8401

Fax: 865-576-5728

E-mail: reports@adonis.osti.gov

Web site: http://www.osti.gov/contact.html

This report was prepared as an account of work sponsored by an agency of the United States government. Neither the United States government nor any agency thereof, nor any of their employees, makes any warranty, express or implied, or assumes any legal liability or responsibility for the accuracy, completeness, or usefulness of any information, apparatus, product, or process disclosed, or represents that its use would not infringe privately owned rights. Reference herein to any specific commercial product, process, or service by trade name, trademark, manufacturer, or otherwise, does not necessarily constitute or imply its endorsement, recommendation, or favoring by the United States government or any agency thereof. The views and opinions of authors expressed herein do not necessarily state or reflect those of the United States government or any agency thereof. 


\section{ACKNOWLEDGEMENTS}

Funding for this project was provided by the California Energy Commission's Public Interest Energy Research program through the Lawrewnce Berkeley National Laboratory operated under U. S. Department of Energy under contract DE-AC02-05CH1 1231. The support and confidence provided by the PIER project managers Chris Scruton and Nancy Jenkins is very much appreciated by the "Cool Roofs" team Hashem Akbari, Paul Berdahl, Ronnen Levinson, and Steve Weil from LBNL and André Desjarlais and William Miller from ORNL. The Tile Roofing Institute and its affiliate members provided the clay and concrete tile. They also provided valuble assistance installing the clay and concrete tile on the respective steep-slope assemblies. Their financial support and guidance are greatly appreciated. 


\section{TABLE OF CONTENTS}

LIST OF FIGURES …………………………………………………………………….... vii

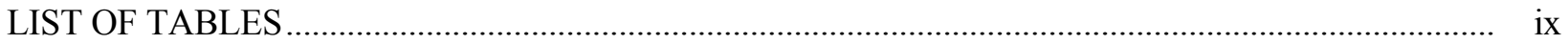

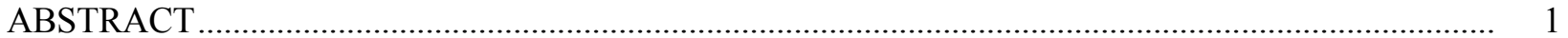

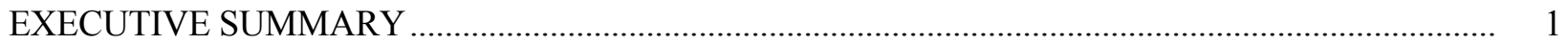

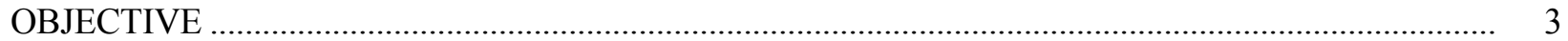

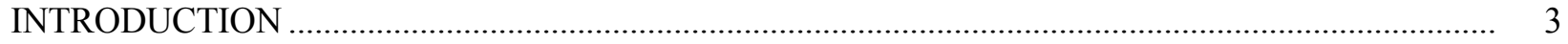

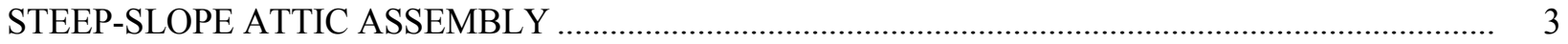

Configuration of Clay and Concrete Tile ……………………………………………………….... 4

Instrumentation for Attic Assembly ............................................................................................... 6

Instrumentation for Sub-Tile Venting ............................................................................................. 8

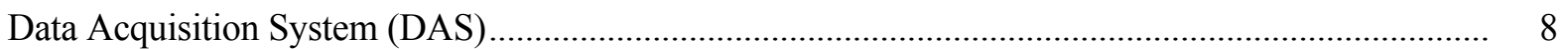

Solar Reflectance and Thermal Emittance Instruments ........................................................................... 9

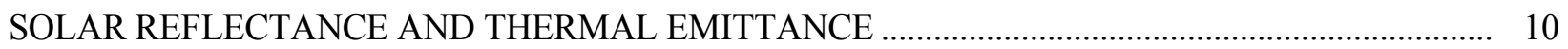

Effects of Climatic Soiling ................................................................................................. 10

Cool Roof Color Materials (CRCMs) ………………………………………………………...... 11

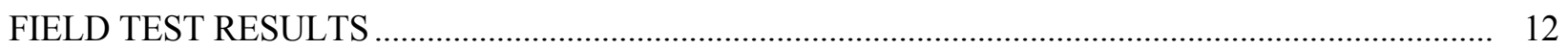

Cooling Season Field Performance ………………………………………………………... 13

Effects of Opening the Ridge Vent..................................................................................... 15

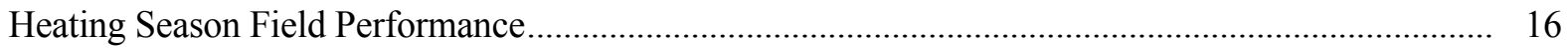

Thermal Mass Effects...………………………………………………………………… 18

Venting the Underside of Tile Roofs.......................................................................................... 19

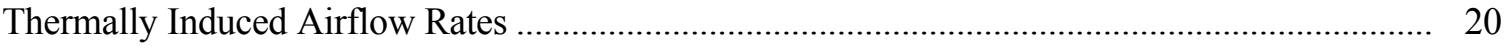

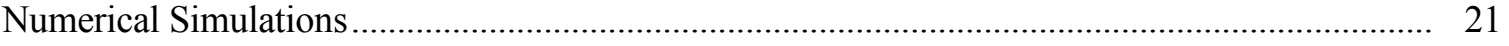

Airflow Measurements Using Tracer Gas ............................................................................. 23

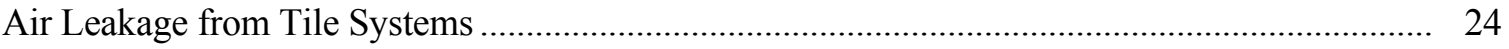

ATTICSIM MODEL ……………………………………………………………………. 25

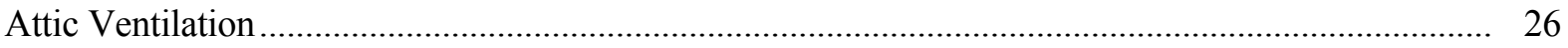

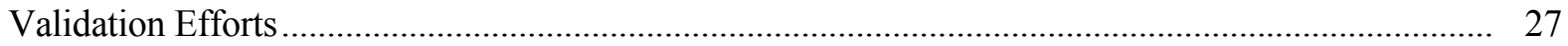

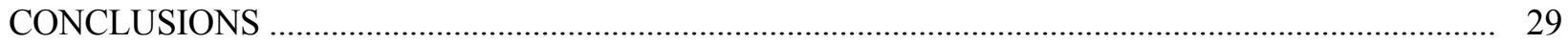

RECOMMENDATIONS ………………………………………………………………... 30

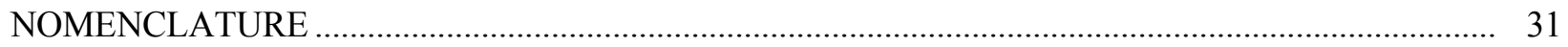




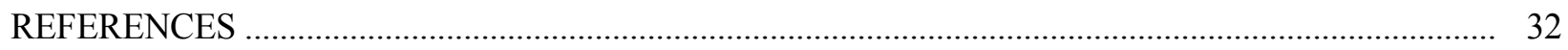

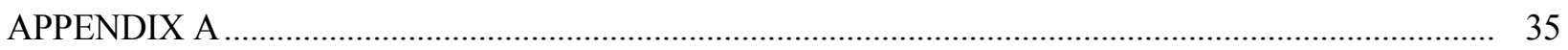

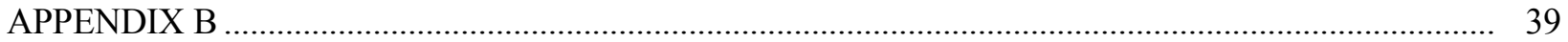




\section{LIST OF FIGURES}

1. Envelope Systems Research Apparatus is a one-story building for testing lowand steep-slope roof products.

2. An assembly of steep-slope attics was placed on top of the ESRA and clay and concrete tile were installed by the Tile Roofing Institute.

3. Construction of the roof deck showing battens and counter-battens for attaching the slate tile and the parapets used to limit airflows on the underside of the tile to within a given test roof.

4. S-Mission clay and concrete tile are designed to have a gap between overlaid tiles

5. The location of temperature, relative humidity, and heat flow measures made on each attic assembly....

6. Heat flux transducer embedded in the roof deck for measuring the heat flow penetrating through the roof tile and into the attic.

7. Setup of attic assembly showing construction materials, instrumentation, and polyisocyanurate insulation used to isolate attic from adjacent attics.

8. Instrumentation used on the underside of the tile roofs for validating heat transfer correlations predicting the heat transfer driven by thermally induced airflows.

9. Solar reflectance of the clay and concrete tile exposed on the ESRA.

10. Solar reflectance of clay tile exposed at weathering sites in California...

11. Cooltile IR Coating ${ }^{\mathrm{TM}}$ developed by Joe Riley, LBNL, and ORNL

12. Heat penetrating the tile roof of each attic assembly on the ESRA; the ridge vent was closed.

13. S-Mission tile reduced the integrated daytime roof heat gain by 50 to $75 \%$ of the gain for the asphalt shingle roof.

14. Bulk air temperatures underneath the S-Mission clay and the concrete slate tile for two different summer days, one with the ridge vent open and the other with the ridge vent closed.

15. Heat penetrating through the roof deck of the S-Mission clay tile and the concrete slate tile with and without venting of the roof deck.

16. Roof deck heat flow for two consecutive days in January 2005; ridge vent is closed.

17. Integrated heat flow measured through the roof deck for all tile and shingle roofs during the month of January 2005.

18. Heat transfer phenomena occurring on the underside of roof tile

19. Numerical simulations for channel flow with and without battens fastened to the underside of tile (the top plate). The channel is at an incline of $30^{\circ}$ (5-in. rise for every $12 \mathrm{in}$. of run), and the top plate is $30^{\circ} \mathrm{F}$ warmer than the bottom plate.

20. Concentration of $\mathrm{CO}_{2}$ measured under the slate tile roof with batten and counter-battens.

21. The leakage of air from the underside of the slate and S-Mission clay tile roofs. 25 
22. AtticSim predicted the attic air temperature of the steep-slope attic assembly modeled as a shed roof with and without ridge venting of the shingle roof.

23. Validation of AtticSim against field measures of the ceiling heat flux gleaned from the ESRA steep-slope roof assembly with a direct-nailed shingle roof.

24. Validation of AtticSim against field measures of the surface temperatures for the asphalt shingles gleaned from the ESRA steep-slope roof assembly. 


\section{LIST OF TABLES}

1. Clay and concrete tile placed on the ESRA's Steep-Slope Attic Assembly.......................... 5

2. Airflow rate and bulk velocity measured at the center of each attic assembly and under the clay and concrete tile roofs using $\mathrm{CO}_{2}$ as a tracer gas.

3. Air infiltration and exfiltration from the S-Mission clay (SR54E90) and the slate concrete (SR13E83) tile roof systems..

4. July 2005 attic temperatures and cumulative heat flows through the roof deck and ceiling of the attic assemblies having both ridge and sub-tile venting .

5. January 2005 attic temperatures and cumulative heat flows through the roof deck and ceiling of the attic assemblies with the ridge closed to attic and sub-tile ventilation. 



\title{
Steep-Slope Assembly Testing of Clay and Concrete Tile Roofs with and without Cool Pigmented Colors
}

A new generation of roofing products are being introduced to the market for bringing relief to homeowners and utilities alike. Cool color pigments used to color paints are reducing the amount of energy needed to cool buildings, which in turn helps power companies reduce hot-weather energy consumption. Cool color pigments will also positively impact the environment by helping reduce carbon dioxide emissions, metropolitan heat buildups, and urban smog.

Industry researchers, including those working with the Department of Defense, developed the first prototype cool color pigments for military camouflage to match the visible and the near-infrared reflectance of background foliage. The high infrared reflectance of these pigments can be exploited to manufacture roofing materials that reflect more sunlight than conventional-pigmented roofing products. Therefore, Oak Ridge National Laboratory (ORNL) and the Lawrence Berkeley National Laboratory (LBNL) initiated a three-year "Cool Roof Color Materials" (CRCMs) project to bring cool-colored roofing materials to the roofing market. ORNL, with assistance from LBNL and in conjunction with pigment (colorant) and roof manufacturers, selected appropriate CRCMs, applied them to roofing materials, and field-tested the roof products. Testing occurred at demonstration homes and seven weathering farms in California and at the campus of the Buildings Technology Center (BTC) using the steep-slope attic assembly on the Envelope Systems Research Apparatus (ESRA).

The BTC completed two years of field-testing clay and concrete tile on the ESRA. The center is reporting the results for this phase of work to complete Task 2.6.3 as part of the deliverables for the Public Interest Energy Research (PIER) project "Cool Roof Colored Materials" sponsored by the California Energy Commission (CEC).

\begin{abstract}
Cool color pigments and sub-tile venting of clay and concrete tile roofs significantly impact the heat flow crossing the roof deck of a steep-slope roof. Field measures for the tile roofs revealed a $70 \%$ drop in the peak heat flow crossing the deck as compared to a direct-nailed asphalt shingle roof. The Tile Roofing Institute (TRI) and its affiliate members are keenly interested in documenting the magnitude of the drop for obtaining solar reflectance credits with state and federal "cool roof" building efficiency standards. Tile roofs are direct-nailed or are attached to a deck with batten or batten and counter-batten construction. S-Misson clay and concrete tile roofs, a medium-profile concrete tile roof, and a flat slate tile roof were installed on fully instrumented attic test assemblies. Temperature measures of the roof, deck, attic, and ceiling, heat flows, solar reflectance, thermal emittance, and the ambient weather were recorded for each of the tile roofs and also on an adjacent attic cavity covered with a conventional pigmented and directnailed asphalt shingle roof. ORNL measured the tile's underside temperature and the bulk air temperature and heat flows just underneath the tile for batten and counter-batten tile systems and compared the results to the conventional asphalt shingle.
\end{abstract}

\section{EXECUTIVE SUMMARY}

An assembly of steep-slope attics having shed-type roofs was installed on top of the ESRA for fieldtesting clay and concrete tile roofs. The attics are adjacent to one another, and their shed roofs face directly south. The footprint for each attic is about $16 \mathrm{ft}$ long by $5 \mathrm{ft}$ wide. Roof slope was set at 4 in. of rise for every $12 \mathrm{in}$. of run ( $18.4^{\circ}$ pitch). Soffitt and ridge venting are provided with vent openings of 1:300. The steep-slope assembly was field-tested for a summer with the ridge vent closed to simulate 
conventional construction in the western states and with the ridge vent open the following summer to observe whether an unimpeded airflow under the tile (sub-tile venting) and attic ventilation would further improve the thermal performance of the tile roofs.

A high-profile S-Mission clay tile with cool pigmented colors, two different styles of high-profile terracotta concrete tiles, a medium-profile concrete (the same as that tested in California demonstrations), and a flat concrete slate tile were installed on the attic assemblies by the TRI. The clay S-Mission tile and the medium-profile concrete tile were direct-nailed to the roof deck, a high-profile S-Mission concrete tile was spot-adhered with foam to the roof deck, the flat concrete slate tile was fastened to a batten and counter-batten system, and another concrete S-Mission tile was fastened to battens. A sixth attic assembly has a conventional asphalt shingle roof for comparing roof and ceiling heat flows.

After two full years of exposure to the East Tennessee climate, the clay and concrete tile showed no noticeable loss in solar reflectance. However, two years of exposure in the more dusty California climates of Colton and El Centro caused the solar reflectance for clay tile to drop about $10 \%$ of its initial values. Dust and urban pollution in California's urban areas soil the materials more than conditions in the lesspopulated sections of the state, and the loss of reflectance is most severe for samples exposed at the slope of $2 \mathrm{in.} \mathrm{of} \mathrm{rise} \mathrm{per} 12 \mathrm{in.} \mathrm{of} \mathrm{run.} \mathrm{Increasing} \mathrm{the} \mathrm{slope} \mathrm{reduced} \mathrm{the} \mathrm{soiling} \mathrm{because} \mathrm{the} \mathrm{dust} \mathrm{is} \mathrm{probably}$ blown away by the strong California winds. Therefore, we believe roof slope affects the loss of reflectance, with the steeper slopes showing less loss in reflectance. Thermal emittance of samples exposed at ORNL and at California sites remained relatively constant at about 0.85 .

Field results for the combination of sub-tile venting and improved solar reflectance offered by CRCMs are proving that tile roofs are energy-efficient cool roof products. The Environmental Protection Agency (EPA), the Leadership in Energy and Environmental Design (LEED), and the many state energy offices should therefore offer energy cridits for roofs using sub-tile venting and cool pigmented colors.

The clay tile field tested at ORNL reduced the peak heat transfer penetrating the roof deck at solar noon by about $70 \%$ of the heat penetrating through the deck of the attic covered with an asphalt shingle roof. Subsequently, the heat penetrating the ceiling of the non-vented attic assembly was reduced by about $60 \%$ of that entering through the ceiling of the non-vented attic assembly with asphalt shingles. The improved performance is due to the tile's high solar reflectance with CRCMs and to the venting occurring on the underside of the clay tile roof.

Field data collected at peak solar loading for concrete tile roofs at ORNL having about the same solar reflectance and thermal emittance as the control asphalt shingle demonstrate that venting the roof deck proportions to about 24 points of solar reflectance. Deck venting caused a significant $50 \%$ reduction in the heat penetrating the conditioned space compared to the direct-nailed asphalt shingle roof that is in direct contact with the roof deck. Opening the ridge vent of the attics caused more heat to be exhausted out the ridge for both the S-Mission clay and the slate tile systems and therefore further improved the performance of the two tile roofs. The effect was more pronounced for the slate tile than observed for the S-Mission tile because the slate tile has less air leakage between tiles as determined by tracer gas experiments.

During January winter exposure, the thermal mass and the tile's air channel have reduced the heat loss from the roof to the point that the heat loss from the ceiling of the tile roofs is about the same as the loss for the asphalt shingle roof, implying that the tile roofs are negating the heating penalty associated with a cool roof in Tennessee's moderate climate having $3662 \mathrm{HDD}_{65}$ and $1366 \mathrm{CDD}_{65}$.

Numerical simulations of the inclined air channel formed by tile roof systems demonstrated that naturally induced flow can be expected at very low roof slopes and very low temperature differences, well below those experienced in roofing systems. The AtticSim computer tool was validated against the steep-slope attic assembly with direct-nailed asphalt shingles. The model effectively predicted the surface temperature of the shingles, the attic air temperature, and, as result, the heat flow penetrating into the 
conditioned space. Efforts are continuing to modify the code for predicting the effects of the airflow occurring on the underside of the tile roof. Correlations by McAdams (1954), Brinkworth (2000), and simple boundary layer theory for a constant solar flux are predicting reasonable heat transfer measures within the inclined air channel. The measures of airflow determined from the tracer gas experiments match well the back-calculated values deduced from the McAdams(1954), Brinkworth (2000), and simple boundary layer theory correlations. We therefore have good representative airflow measures for sub-tile venting and are in good position to implement an algorithm formulated after the work by Brinkworth (2000) for use in AtticSim to predict thermal performance of tile roofs.

\section{OBJECTIVE}

Thermal performance, solar reflectance, and thermal emittance data were collected from the ESRA to document the energy savings of clay and concrete tile roofs to determine both the benefits of CRCMs and of venting the underside of tile roofs, between the tile and roof deck.

\section{INTRODUCTION}

The TRI, ORNL, and LBNL are working together to quantify and report the potential energy savings for concrete and clay tile roofs. TRI and its affiliate members are keenly interested in specifying tile roofs as cool roof products, and they want to know the effects of the tile's solar reflectance and of venting the underside of a tile roof. Parker, Sonne, and Sherwin (2002) demonstrated that a Florida home with a "white reflective" barrel-shaped concrete tile roof used 22\% less annual cooling energy than an identical and adjacent home having a dark absorptive asphalt shingle roof. The cost saving due to the reduced use of comfort cooling energy was about $\$ 120$, or about $6.7 \varnothing$ per square foot per year.

The venting of the underside of a tile roof also provides thermal benefits for comfort cooling. Residential roof tests by Beal and Chandra (1995) demonstrated a 45\% reduction in the daytime heat flux penetrating a counter-batten tile roof as compared to a direct-nailed shingle roof. Parker, Sonne, and Sherwin (2002) observed in their study that a moderate solar reflectance terra cotta barrel-shaped tile reduced the home's annual cooling load by about $8 \%$ of the base load measured for an identical home with asphalt shingle roof that was adjacent the home with terra cotta tile. These reported energy savings are attributed in part to thermally driven airflow within the air channel formed by the underside of the tile and the roof deck. The airflow is driven by buoyancy and/or wind driven forces. The air channel also provides an improvement in the insulating effect of the roofing system. Measuring and correctly modeling the heat flow on the underside of a tile roof are key hurdles for predicting the roof's thermal performance. The heat transfer can switch from conduction to single-cell convection to Bénard cell convection dependent on the aspect ratio made by the underside of the tile and the roof deck, the slope of the roof, and the weather. The coexistence and competition of the various modes of heat transfer require experimental measurements and numerical simulations.

Therefore, a combined experimental and analytical approach was conducted with the collection of two years of field data - one year with the ridge vent closed to all attic cavities to mimic conventional construction and the second year with the ridge vent open. Results are shown to report the potential energy savings for residential homes having concrete and clay tile roofs.

\section{STEEP-SLOPE ATTIC ASSEMBLY}

The ESRA is a one-story building used to expose large areas of low-slope and steep-slope roofs to East Tennessee's climate. Two sides of the building are mostly below grade, while the other two sides are mostly above grade (Fig. 1). The interior of the ESRA is heated and cooled to a constant temperature of 


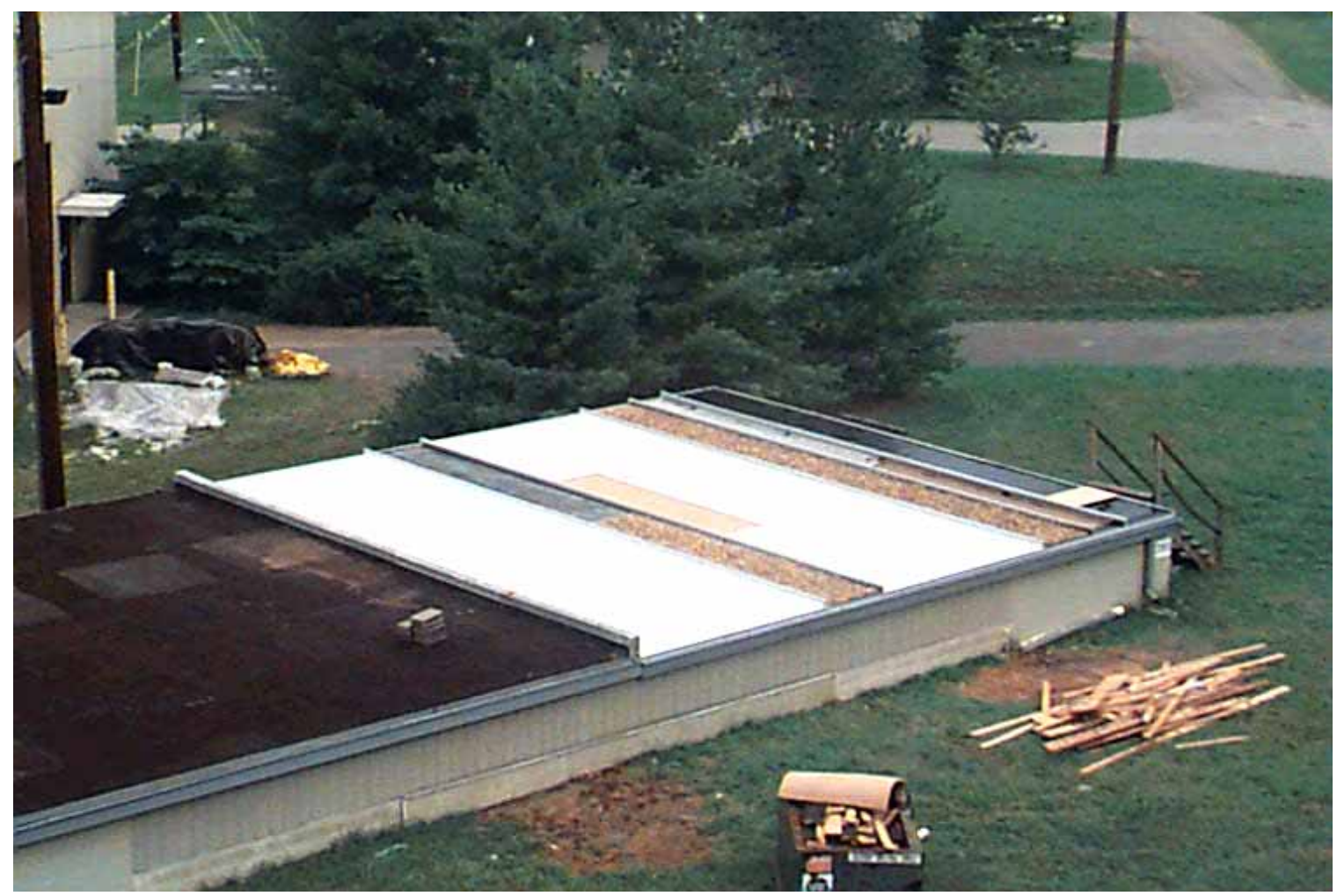

Fig. 1. Envelope Systems Research Apparatus (ESRA) is a one-story building for testing low- and steep-slope roof products.

$70^{\circ} \mathrm{F}$ year-round. The long axis of the building is oriented east to west, and the test roofs on the ESRA face directly south to receive full exposure from the sun.

\section{Configuration of Clay and Concrete Tile}

Members of TRI installed clay and concrete tile on a fully instrumented steep-slope attic assembly (Fig. 2). High-profile S-Mission clay and concrete tile, medium-profile concrete, and a flat concrete slate tile were exposed to East Tennessee's climate for two full years. The clay S-Mission tile and the mediumprofile concrete tile were direct-nailed to the roof deck, high-profile S-Mission concrete tile was spotadhered with foam to the roof deck, the flat concrete slate tile was fastened to a batten and counter-batten system, and another concrete S-Mission tile was fasten to battens (Table 1). The sixth lane (see far left lane in Fig. 2) has a conventional asphalt shingle roof for comparing energy savings. The tile roofs are approximately $5 \mathrm{ft}$ wide with $16 \mathrm{ft}$ of footprint. Table 1 and Appendix A provide the salient features of the test concrete and clay tiles. All tiles, whether direct-nailed or installed on battens, have a sub-tile venting occurring up along the underside of the tile traveling from soffitt to ridge and transversely along the width of the test roofs. Parapet partitions with channel flashing were installed between lanes to keep transverse airflows within a given type of tile (Fig. 3).

Each test roof has its own attic cavity with 11 in. of expanded polystyrene insulation installed between adjacent cavities. This reduces the heat leakage between cavities to less than $0.5 \%$ of the solar flux incident at solar noon on a test roof. Therefore, each lane can be tested as a stand-alone entity. Salient features of the ESRA facility are fully discussed by Miller et al. (2002). 


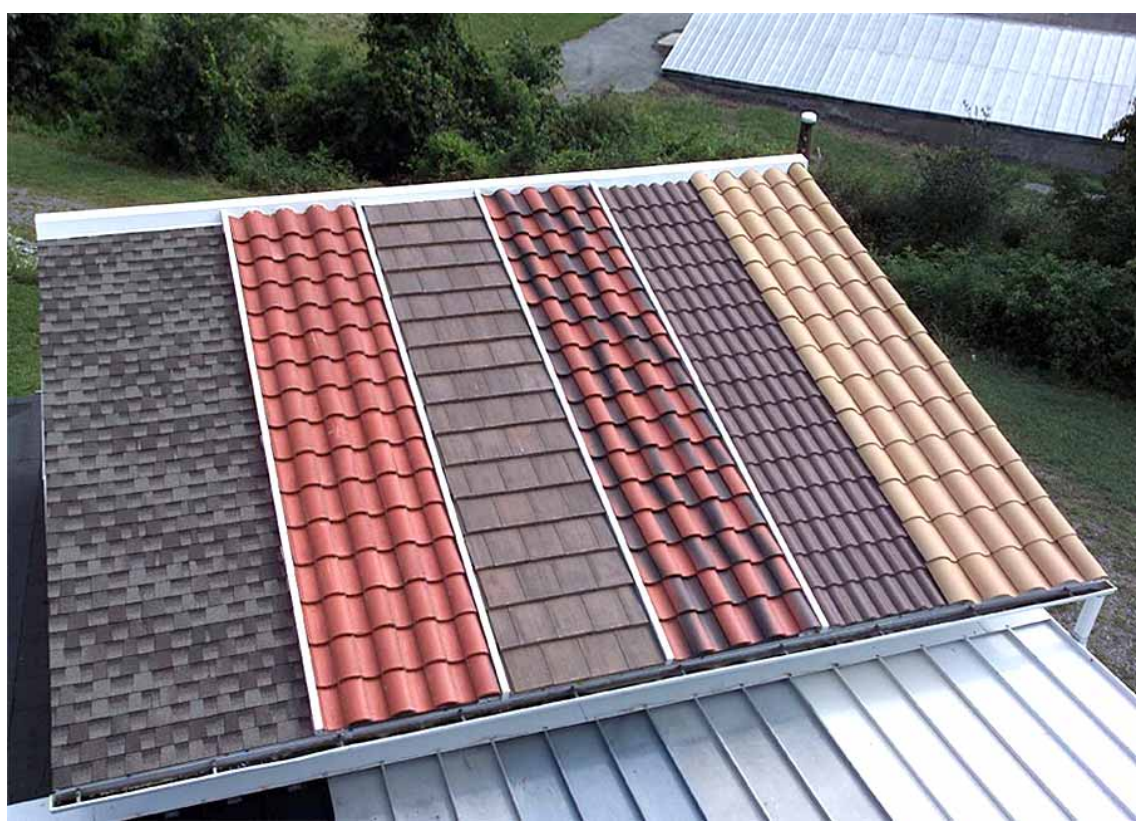

Fig. 2. An assembly of steep-slope attics was placed on top of the ESRA and clay and concrete tile were installed by the Tile Roofing Institute.

Table 1. Clay and concrete tile placed on the ESRA's Steep-Slope Attic Assembly

\begin{tabular}{|c|c|c|}
\hline Roof Cover & Attachment to Deck & Reflectance Emittance \\
\hline & & $\mathrm{SR} x x \mathrm{E} y y^{1}$ \\
\hline S-Mission Clay & Direct to Deck & SR54E90 \\
\hline Medium-Profile Concrete & Direct to Deck & SR10E93 \\
\hline S-Mission Concrete & Spot Adhered to Deck Using Foam & SR26E86 \\
\hline Slate Concrete & Counter-Batten and Batten & SR13E83 \\
\hline S-Mission Concrete & Batten & SR34E83 \\
\hline Asphalt Shingle & Direct to Deck & SR10E89 \\
\hline
\end{tabular}

${ }^{1}$ SR $x x$ states the solar reflectance of a new sample. Eyy defines the thermal emittance of the new sample. For example, the asphalt-shingle roof is labeled SR10E89; its freshly manufactured surface properties are therefore 0.10 -reflectance and 0.89-emittance.

As mentioned, a sub-tile venting occurs up along the underside of the tile roofs because of the design of the tile and the construction of the roof deck. The batten and batten with counter-batten installations provide a unique inclined air channel running from the soffit to the ridge. The bottom surface of the air channel is formed by the roof deck and 30\# felt and is relatively in plane and smooth. The top surface is created by the underside of the roofing tiles and is broken at regular intervals by a batten ${ }^{1}$ wood furring strip (into which the tiles are fastened). For batten and counter-batten construction, the counter-batten is fastened to the roof deck and run from soffit to ridge, and the batten is nailed on top of the counter-battens (Fig. 3). The underside of the roof tiles establishes the upper surface of the inclined air channel. Tiles are designed with a gap at the respective overlap where one tile lies atop the other. The design allows wind pressures to equalize for reducing wind uplift (Fig. 4). The design further complicates solution of the heat transfer, because an accurate prediction of the airflow is required to predict the heat transfer crossing the roof boundary.

\footnotetext{
${ }^{1}$ Battens are either fastened directly to roof deck or fastened atop a counter-batten. Battens run parallel to the roof's ridge.
} 


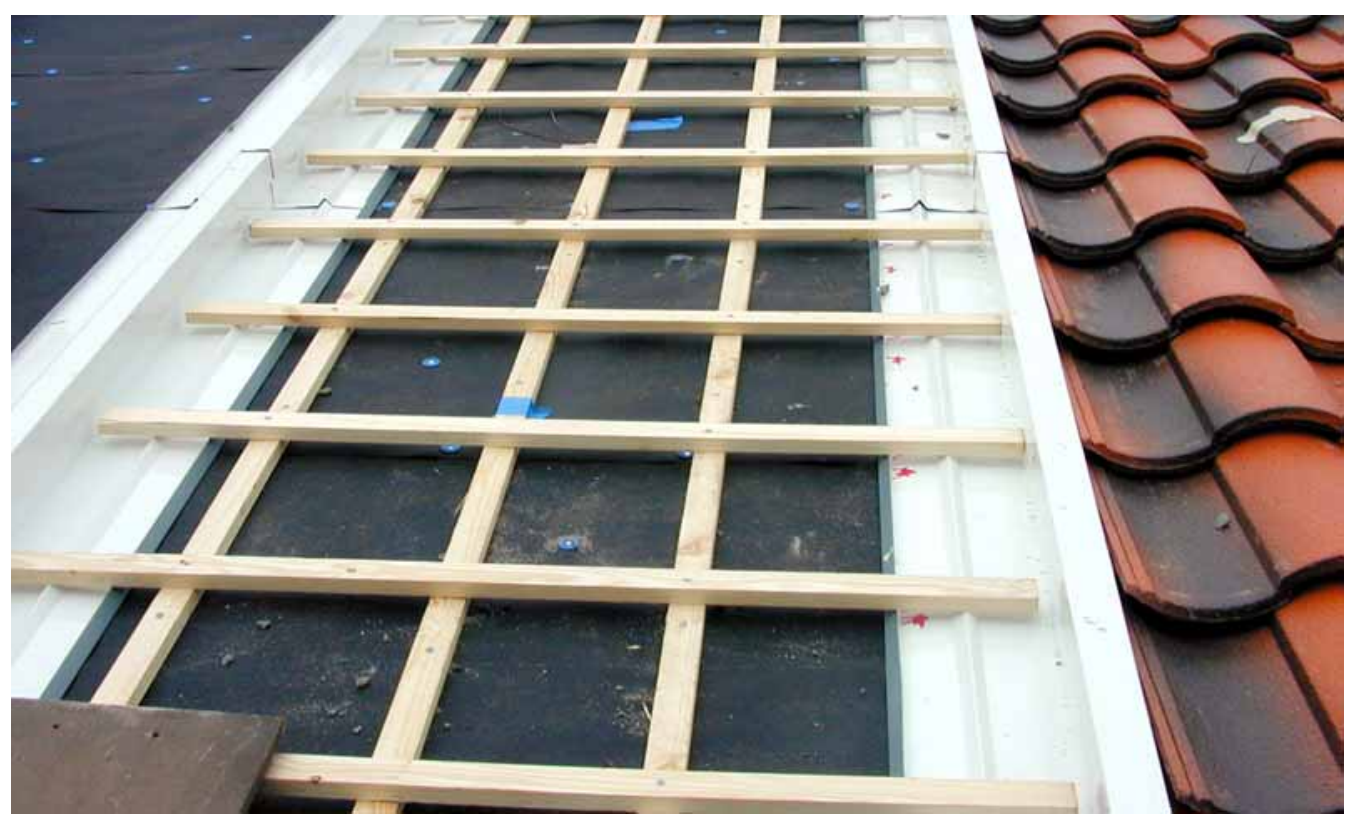

Fig. 3. Construction of the roof deck showing battens and counter-battens for attaching the slate tile and the parapets used to limit airflows on the underside of the tile to within a given test roof.

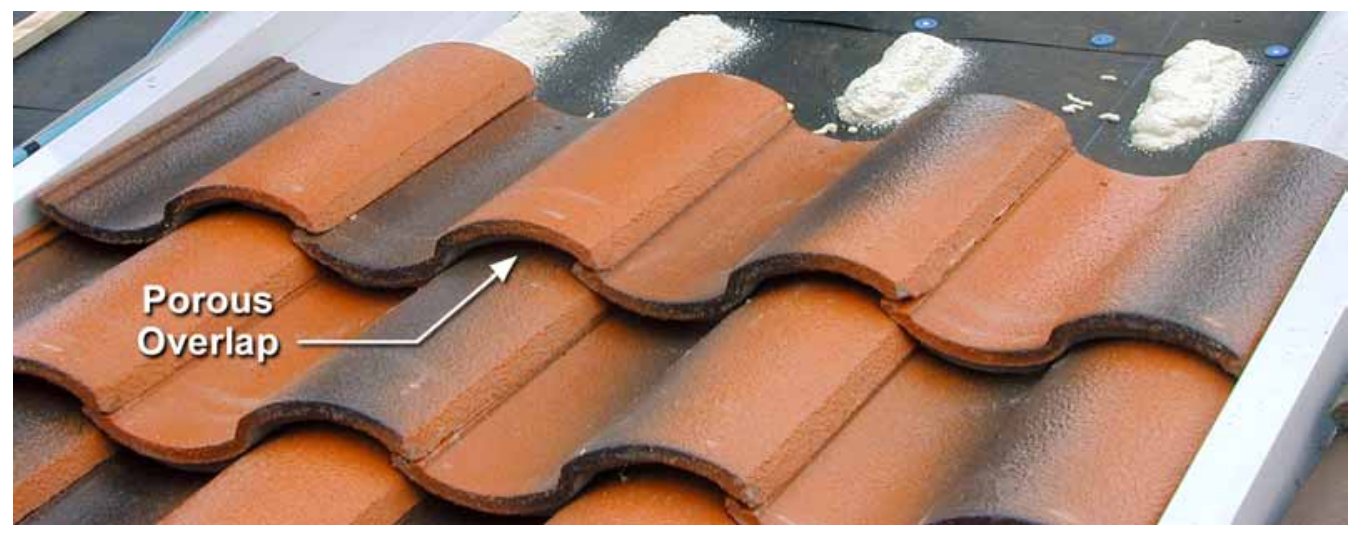

Fig. 4. S-Mission clay and concrete tile are designed to have a gap between overlaid tiles.

\section{Instrumentation for Attic Assembly}

The surface and underside temperatures of the tile, the temperatures of the roof deck on both sides of the oriented strand board (OSB), and the heat flux transmitted through the roof deck are directly measured (Fig. 5) and recorded by a data acquisition system (DAS). All roof decks have a 2 -in-square by 0.18 -in.deep routed slot (Fig. 6) with a heat flux transducer (HFT) inserted to measure the heat flow crossing the deck. Each HFT was placed in a guard made of the same OSB material used in construction and calibrated using a FOX 670 Heat Flow Meter Apparatus to correct for shunting effects (i.e., distortion due to three-dimensional heat flow). The attic cavities also have an instrumented area in the ceiling for measuring the heat flows into the conditioned space. The ceiling consists of a metal deck, a 1-in.-thick piece of wood fiberboard lying on the metal deck, and a $1 / 2$-in.-thick piece of wood fiberboard placed atop the 1-in. piece (Fig. 7). The HFT for measuring ceiling heat flow is embedded between the two pieces of wood fiberboard. It was also calibrated in a guard made of wood fiberboard before being placed in field service. 


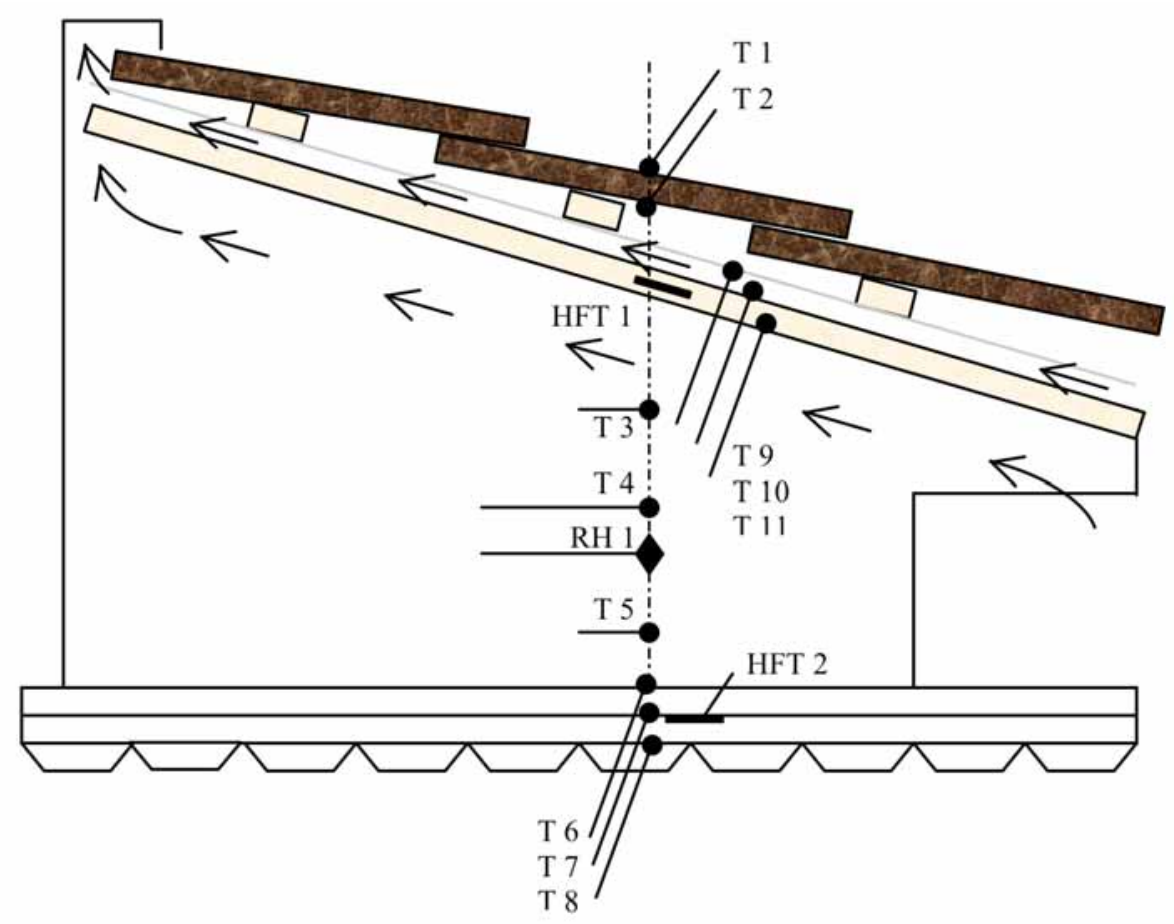

Fig 5. The location of temperature, relative humidity, and heat flow measures made on each attic assembly.

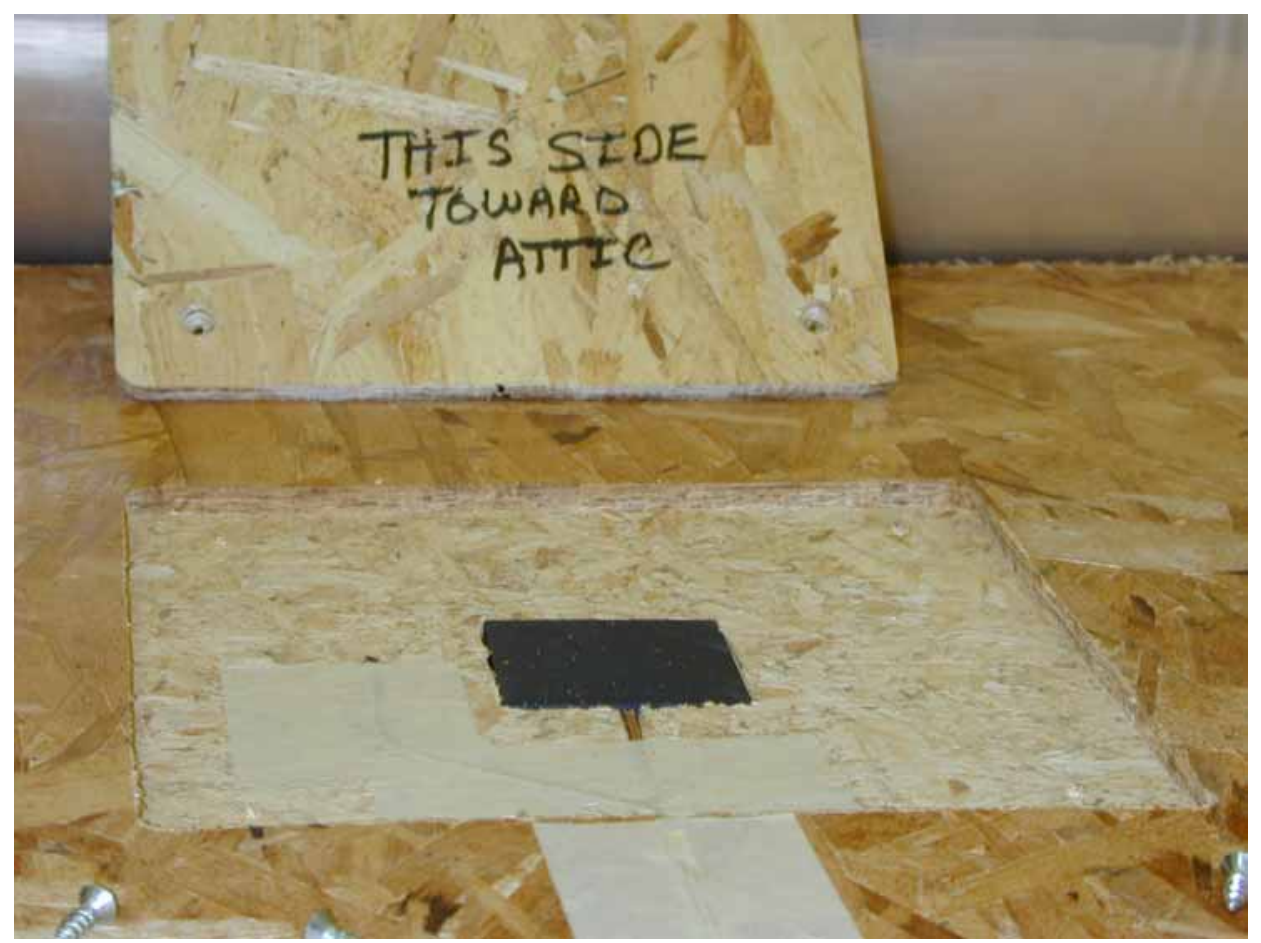

Fig. 6. Heat flux transducer embedded in the roof deck for measuring the heat flow penetrating through the roof tile and into the attic. 


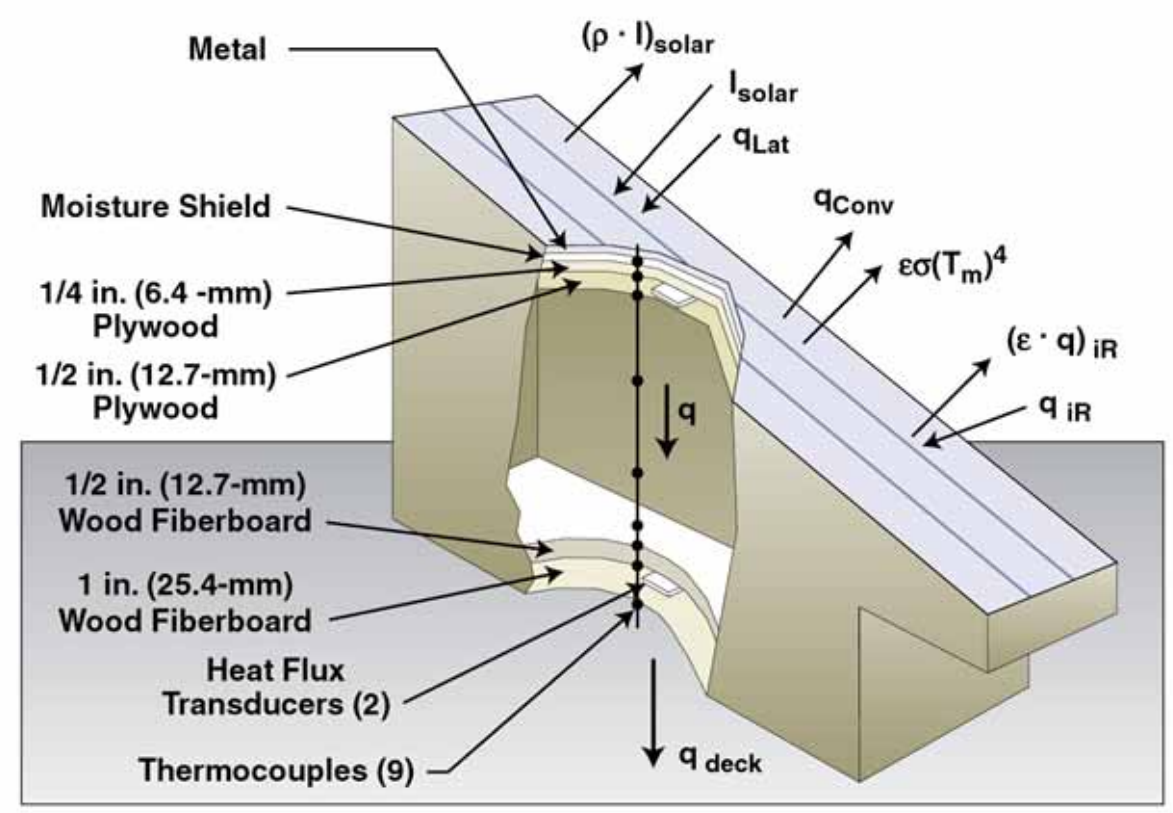

Fig. 7. Setup of attic assembly showing construction materials, instrumentation, and polyisocyanurate insulation used to isolate attic from adjacent attics.

\section{Instrumentation for Sub-Tile Venting}

Tile roofs are traditionally offset from the roof deck, and the convection heat transfer in this space may be mixed, being a combination of forced and natural convection heat transfer. Data on the mixed-convection phenomena are sparse because buoyancy effects can cause oscillations in the inertia flow field, which make convergent numerical solutions difficult to obtain. Therefore, the effect of sub-tile venting is a key measurement issue that required added instrumentation.

The S-Mission clay tile and flat slate roofs have thermocouples and HFTs at four stations starting at the soffitt and spaced evenly about $4 \mathrm{ft}$ apart up to the ridge to measure the bulk air temperatures and the heat flux near the underside of the tile (Fig. 8). These measurements are used to gage the convective heat transfer within the air channel made by the underside of the tile and the roof deck. On a typical warm, sunny day, the irradiance from the sun will penetrate the tile roof and will cause a net inflow of heat into the air channel, and a portion of this heat is conducted into the attic space. The penetration of heat into the attic as measured by the HFTs is defined as positive heat flow. Heat leaving the attic or conditioned space is defined as negative heat transfer.

\section{Data Acquisition System}

A 700-MHz Pentium III computer collected field data using FIX DMACS version 7.1 software supported by Windows version 2000. The code scanned all instruments every $15 \mathrm{~s}$ and electronically recorded averages at 15-min intervals to a historical database within the FIX DMACS hierarchy. Data were retrieved weekly from the historical database and written to a spreadsheet for combination with the weather data and in preparation for later data reduction and analysis. 


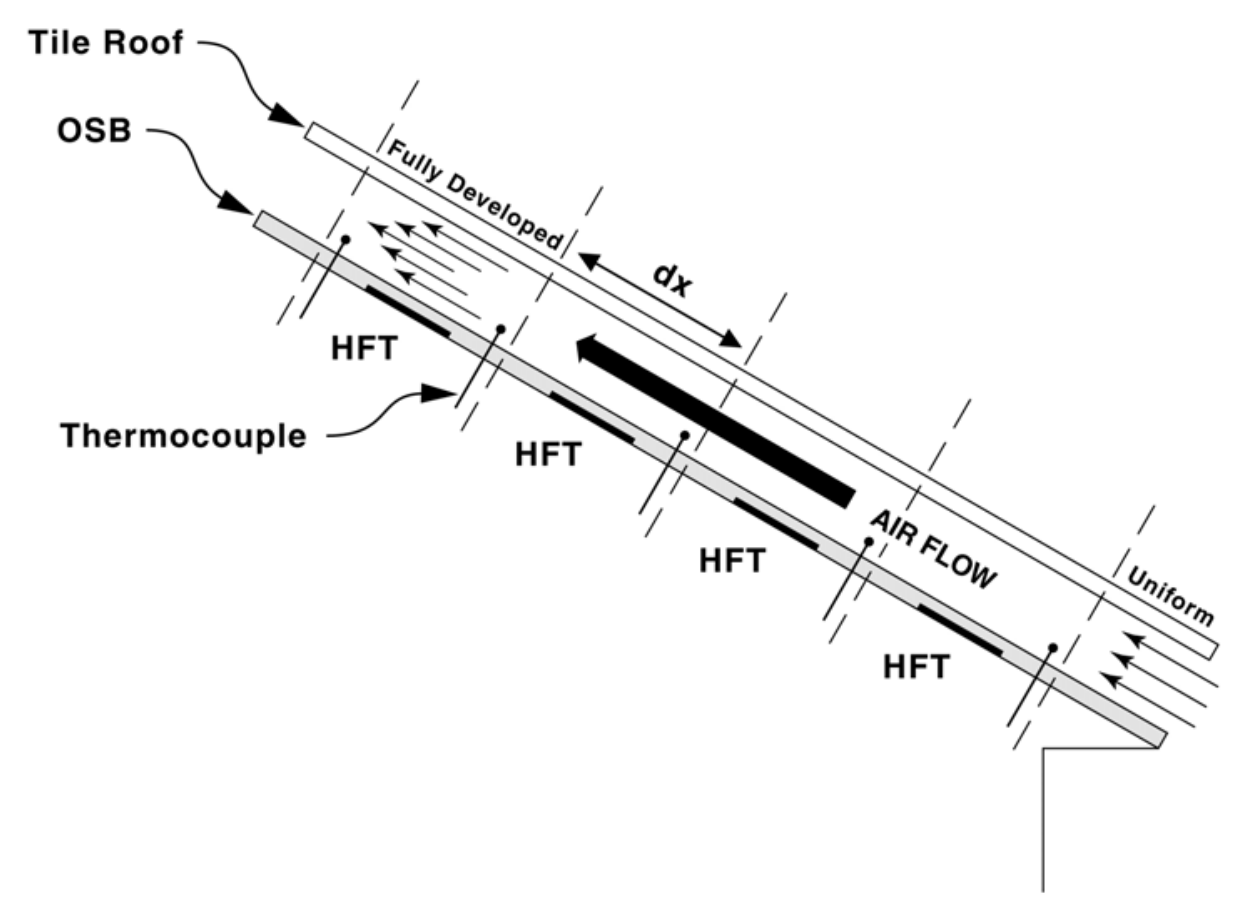

Fig. 8. Instrumentation used on the underside of the tile roofs for validating heat transfer correlations predicting the heat transfer driven by thermally induced airflows.

\section{Solar Reflectance and Thermal Emittance Instruments}

A Device and Services solar spectrum reflectometer was used to measure the solar reflectance (total hemispherical reflectance over spectrum of sun's energy) of the roof samples. The device uses a tungsten halogen lamp to diffusely illuminate a sample. Four detectors, each fitted with differently colored filters, measure the reflected light in different wavelength ranges. The four signals are weighted in appropriate proportions to yield the total hemispherical reflectance. The device was proven accurate to within \pm 0.003 units (Petrie et al. 2000) through validation against the ASTM E-903 method (ASTM 1996). However, because the CRCMs exhibit high infrared reflectance, some of the field samples were also measured at LBNL using a spectrometer to check the portable reflectometer. The average absolute difference between the Device and Services reflectometer and the spectrometer was about 0.02 points of reflectance, with the spectrometer consistently reading lower than the reflectometer. (For example, the reflectometer measured a solar reflectance of 0.741 for a cool pigment painted metal, while the spectrometer measured 0.73.)

The impact of emittance on roof temperature is as important as that of reflectance. A portable Device and Services emissometer was used to measure the thermal emittance using the procedures in ASTM C-1371 (ASTM 1997). The device has a thermopile radiation detector, which is heated to $180^{\circ} \mathrm{F}$. The detector has two high- $\varepsilon$ and two low- $\varepsilon$ elements and is designed to respond only to radiation heat transfer between itself and the sample. Because the device is comparative between the high- $\varepsilon$ and the low- $\varepsilon$ elements, it must be calibrated in situ using two standards, one having an emittance of 0.89 , the other having an emittance of 0.06. Kollie, Weaver, and McElroy (1990) verified the instrument's precision as \pm 0.008 units and its accuracy as \pm 0.014 units in controlled laboratory conditions. 


\section{SOLAR REFLECTANCE AND THERMAL EMITTANCE}

The solar reflectance and the thermal emittance of a roof surface are important surface properties affecting the roof temperature, which, in turn, drives the heat flow through the roof. The solar reflectance ( $\rho)$ determines the fraction of the solar radiation incident from all directions that is diffusely reflected by the surface. The thermal emittance $(\varepsilon)$ describes how well the surface radiates energy away from itself as compared to a blackbody operating at the same roof temperature. The thermal emittance is the total hemispherical emittance of electromagnetic radiation over all wavelengths with peak irradiance occurring in the far-infrared region for roof temperatures of the order of $150^{\circ} \mathrm{F}$.

\section{Effects of Climatic Soiling}

Solar reflectance measures of the clay and concrete tile roofs exposed at ORNL were collected quarterly; these data are shown in Fig. 9. The initial solar reflectance and initial thermal emittance are identified for each tile using the abbreviation SRxxEyy described in Table 1. After two years of exposure, the S-Mission tiles (SR54E90, SR26E86 and SR34E83) show little drop in solar reflectance. The mediumprofile concrete (SR10E93) and the slate (SR13E83) tiles actually show slight increases in solar reflectance, as does the asphalt shingle roof due to the accumulation of airborne contaminants. Dust tends to lighten these darker colors. Data for clay tile are also shown for field exposure testing in 3 of the 16 climatic zones of California. The clay samples are identical to those tested at ORNL. They show a loss of solar reflectance that occurs because of climatic soiling. The worst soiling observed occurs in the urban area of Colton and the desert area of El Centro (Fig. 10). However, the crisp and clear alpine climate of McArthur shows the lowest loss of solar reflectance, because fewer contaminants pollute the air. Roof

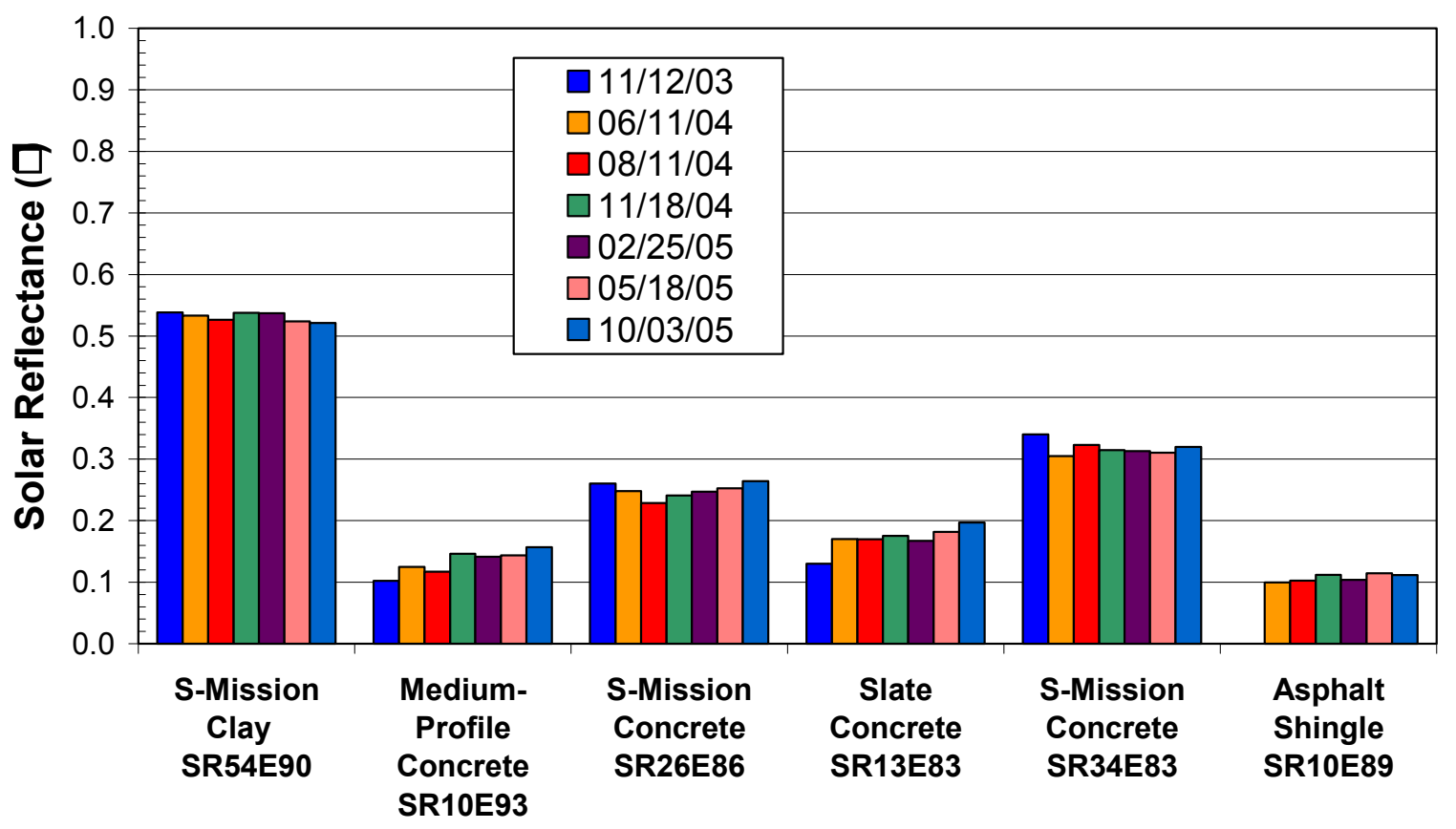

CONCRETE AND CLAY TILES

Fig. 9. Solar reflectance of the clay and concrete tile exposed on the ESRA. 


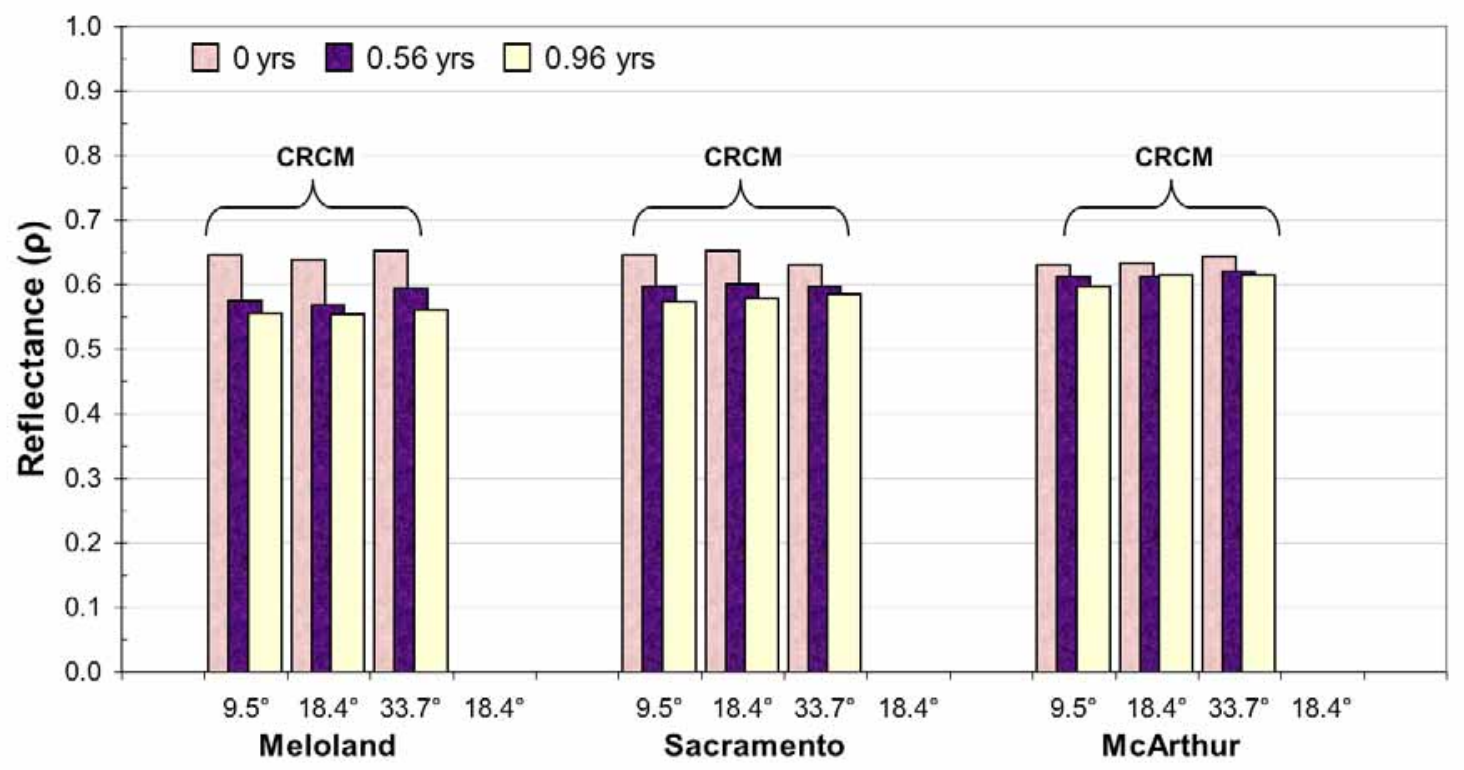

Fig. 10. Solar reflectance of clay tile exposed at weathering sites in California.

slope appears to affect the loss of solar reflectance (Fig. 10). Testing at the slope of 8 in. of rise per $12 \mathrm{in}$. of run $\left(33.7^{\circ}\right.$ slope $)$ has less reflectance loss compared to testing at 2 in. of rise per 12 in. of run $\left(9.5^{\circ}\right)$ for all three exposure sites (Fig. 10). Precipitation is not believed to be the dominant player, especially when one considers that El Centro has less than 3 in. of annual rainfall! Rather, wind may be causing the different losses of solar reflectance as roof slope changes from $9.5^{\circ}$ to $33.7^{\circ}$.

Our emphasis on the long-term benefits of cool roofing systems recognizes the potential for a significant loss in solar reflectance in the first few years of service life. Surface contamination and climatic exposure cause the loss. The results in Figs. 9 and 10 show that exposure testing differed between the western and mid-eastern climates of the United States. The samples from the two regions show that California has more airborne dust than does Tennessee, which causes the greater loss of reflectance in California. East Tennessee's climate caused little, if any, soiling of the nonwhite tiles.

The thermal emittance of the clay and concrete tile has not changed much after 2 years of exposure in California. It remains relatively constant at about 0.85 .

\section{Cool Roof Color Materials (CRCMs)}

The clay tile (SR54E90) tested at ORNL and California exceeds the solar reflectance of all the other tiles (Fig. 9), because it contains complex inorganic color pigments that boost its reflectance in the infrared spectrum. A slurry coating process is used to add color to the surface of a clay tile. Once coated, the clay is kiln-fired, and the firing temperature, the atmosphere, and the pigments affect the final color and solar reflectance [Akbari, et al. (2004a)]. The complex inorganic color pigments, termed here as cool roof color materials, are of paramount importance and will literally revolutionize the roofing industry. The energy and cost savings reported by Parker et al. (2002) for white reflective concrete tile are promising; however, in the residential market, the issues of aesthetics and durability will limit the acceptance of "white" residential roofing. To homeowners, dark roofs simply blend better with the surroundings than their counterpart, a highly reflective "white" roof. What the public is not aware of, however, is that the aesthetically pleasing dark roof can be made to reflect like a "white" roof in the near-infrared spectrum. Miller et al. (2004), Akbari et al. (2004b), and Levinson et al. (2005a and 2005b) provide further details 
about the potential energy benefits, identification, and characterization of dark, yet highly reflective, color pigments.

Coating tile with CRCMs has been successfully demonstrated by American Rooftile Coatings, which applied its Cooltile IR Coating ${ }^{\mathrm{TM}}$ (Appendix B) to several samples of concrete tiles of different colors (Fig. 11). The solar reflectance for all colors tested exceeded 0.40. Most dramatic is the effect of the dark colors. The black coating increased the solar reflectance from 0.04 to 0.41 , while the chocolate brown coating increased from 0.12 to 0.41 , a $250 \%$ increase in solar reflectance! Because solar heat gain is proportional to solar absorptance, the Cooltile IR Coating ${ }^{\text {TM }}$ reduces the solar heat gain by roughly $33 \%$, of that of the standard color, which is very promising. The coating application is a significant advancement for concrete tile, because the alternative is to add the CRCMs to the cement and sand mixture. This requires too much pigment and makes the product too expensive. The coating can certainly help tile roof products comply with legislation being proposed for California's Title 24 building energy efficiency standards for residential buildings. Levinson, Akbari, and Reilly (2004) found that applying the Cooltile IR Coating ${ }^{\mathrm{TM}}$ yielded measurable reductions in roof surface temperature, attic air temperature, and ceiling heat flux for scaled buildings field tested in Riverside, Calif. Levinson predicted that the IR coating would save about $92 \mathrm{kWh}$ /year for a $1500-\mathrm{ft}^{2}$ Fresno home with R-11 attic insulation and would yield a simple payback for the coating within about 5 years.

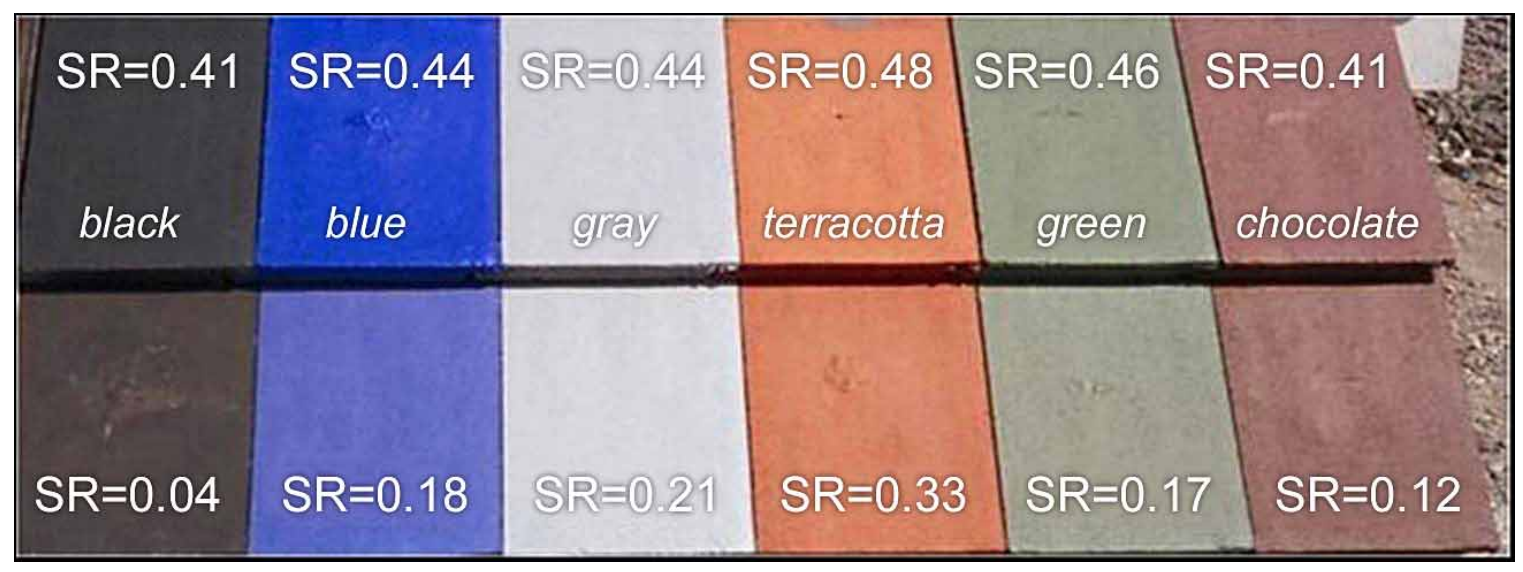

Fig. 11. Cooltile IR Coating ${ }^{\mathrm{TM}}$ developed by Joe Riley, LBNL and ORNL.

\section{FIELD TEST RESULTS}

The multiple hazard protection provided by concrete and clay tile from fire and wind and the superior aesthetics and durability of tile are making these roof materials the preference of homeowners in western and some southern states. Thermal performance data collected from the attic test assembly at ORNL show tile to be an energy-efficient roof product because of the venting occurring on the underside of the tile and also because of the increase in solar refectance achievable with CRCMs.

Venting of attic spaces, and its effect on heat transmission, moisture, and condensation, has been studied at reasonable length, but little has been studied with regard to the venting and flow patterns observed in the inclined channel created by tile roofs. Rose (1995) gives an overview of the evolution of attic venting, and Romero and Brenner (1998) instrumented a test building for the study of ridge venting procedures and the associated flow within the attic space. Though work is scarce on heat transfer within the narrow air channel in counter-batten installations, insight can be gained from the work done on attic ventilation and on experimental studies of heat transfer in inclined ducts. Ozsunar et. al (2001) studied the effects of inclination on convection within a large aspect ratio duct heated from below. Beal and Chandra (1995) studied heat transfer through direct-nailed tile roofs and counter-batten tile roofs compared to direct- 
nailed asphalt shingles. Tile in general reduced heat transmission by $39 \%$ for the direct-nailed roof and by $48 \%$ for the counter-batten roof.

\section{Cooling Season Field Performance}

The clay S-Mission tile (SR54E90), the S-Mission tile spot adhered with foam (SR26E86), and the S-Mission tile on battens (SR34E83) had the least amount of heat penetrating into their respective roof decks (Fig. 12). The roof heat flux data are for two consecutive days of exposure during August 2004 in East Tennessee's hot and humid climate. All three tiles have venting occurring along the underside of the tile's barrel from soffitt to ridge; however, the ridge vent is closed to simulate conventional installations in the western states. Of these three roof systems, the clay tile (SR54E90) had the lowest heat flux through the deck, due primarily to the tile's high solar reflectance. The clay tile reduced the peak heat transfer penetrating the roof deck at solar noon by about $70 \%$ of the energy penetrating through the deck of the attic covered with an asphalt shingle roof. Subsequently, the heat penetrating the ceiling of the attic assembly was reduced by about $60 \%$ of that entering through the ceiling of the attic assembly with asphalt shingles ${ }^{2}$.
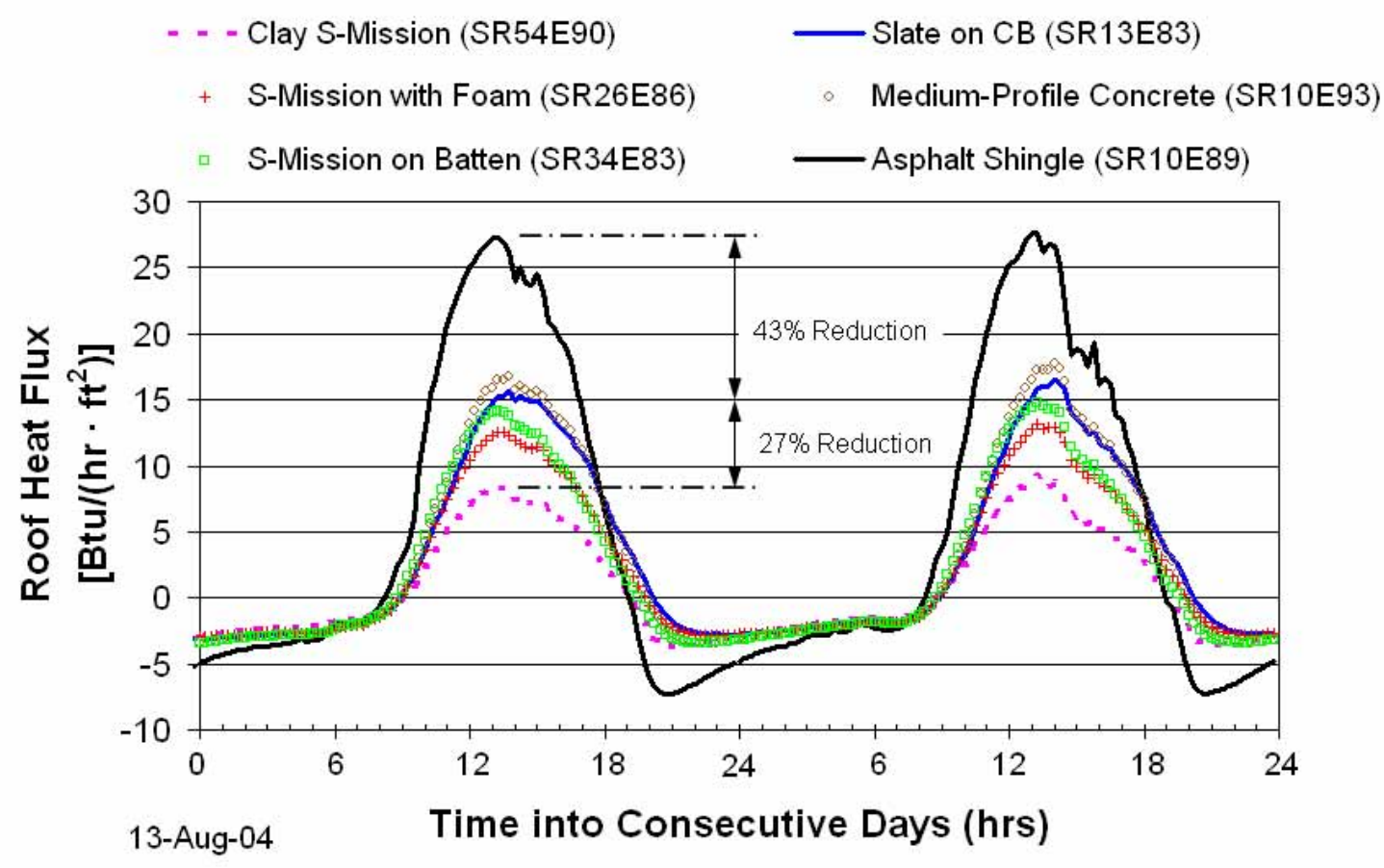

Fig. 12. Heat penetrating the tile roof of each attic assembly on the ESRA; the ridge vent was closed.

The solar reflectance and thermal emittance of the slate roof (SR13E83) and the medium-profile tile (SR10E93) are very similar to that of the asphalt shingle (SR10E89), but the heat transfer through the roof and ceiling of the attic with the slate roof and the medium-profile tile roof are only half that measured for the asphalt shingle roof. The reduction must be due to buoyancy and wind force effects occurring in the inclined air channel that dissipates heat away from the deck. The slate tiles are attached to batten and counter-batten strips, which form the inclined air channel that is about $1 \frac{1}{2} \mathrm{in}$. deep. The medium-profile

\footnotetext{
${ }^{2}$ The ridge vent for the asphalt shingle roof was also closed for the August 2004 comparison to clay and concrete tile roofs field-tested on the ESRA.
} 
tile forms its own half-cylindrical channel of about 0.5 in. radius. It is very interesting that these two dark tile systems (SR13E83 and SR10E91), as compared to the shingle roof (SR10E89), significantly reduce the heat penetrating their respective ceilings. The data in Fig. 12 clearly show the benefit derived from venting the roof deck based solely on the direct comparison of the percent reduction of peak loads (i.e., $\sim 45 \%$ reduction for the SR13E83 or SR10E93 and a 70\% reduction for the SR54E90 tile as compared to the shingle roof). Proportioning the heat reduction due solely to venting (SR10E93 vs SR10E89) to the heat reduction due to solar reflectance and venting (R54E90 vs SR10E89):

$$
\overbrace{\frac{45 \% \text { due to venting }}{70 \% \text { due to venting and SR }}}^{\text {heat reduction }} \cdot\left[\mathrm{SR} 54_{\text {Clay Tile }}-\mathrm{SR} 10_{\text {Shingle }}\right]
$$

yields a venting benefit at solar noon that is equivalent to roughly 30 points of surface reflectance! Hence, the data at peak loading imply that "cool roofing" credits are obtainable through venting the underside of a tile or similarly constructed roof system. The data also clearly show the synergism gained by the solar reflectance of CRCMs (Fig. 12) and the deck venting occurring on the underside of tile roofs. A full month of field data for August 2004 was reduced to better observe the seasonal trends in roof heat transfer for the tile and asphalt shingle roofs. Data for the HFTs embedded in the south-facing roof deck and the ceiling of each attic assembly were integrated over the daylight hours (red bars in Fig. 13), nighttime hours (gray bars in Fig. 13), and the 24-h cycle for HFTs embedded in the ceiling (blue bars in Fig. 13) and summed for the month. Hence, the red and gray bars represent, respectively, the total daytime heat gain and nighttime loss crossing the roof deck during August 2004 exposure. The blue bars represent the total heat transfer into the conditioned space measured from the HFT embedded in the ceiling of each attic assembly.

Results for the unvented attics show that the heat gain entering the asphalt shingle roof is almost double that observed for the medium-profile (SR10E93) and the slate (SR10E83) concrete roofs. Therefore, the effect of venting the underside of the medium-profile and slate tile roofs based on proportioning roof heat transfer (Eq. 1) equates to about 24 points of solar reflectance for the month of August 2004. In other words, an SR34E93 roof with no deck venting would have about the same roof heat transfer as the vented tile (SR10E93) roof.

Again the S-Mission tile roofs have the least amount of heat penetrating the roof deck, with the clay tile (SR54E90) showing best performance. About $4100 \mathrm{Btu} / \mathrm{ft}^{2}$ of roof surface penetrated the shingle roof as compared to only $1127 \mathrm{Btu} / \mathrm{ft}^{2}$ for the clay tile roof, representing a $72 \%$ reduction in roof heat transfer. This, in turn, leads to the reduction in heat transfer observed crossing the ceiling of the two attic assemblies. The heat transfer penetrating the ceiling of the attic with clay tile was about $75 \%$ less than that measured for the heat penetrating the ceiling of the attic with an asphalt shingle roof. It is also interesting to observe that all the tile roofs have less heat loss to the ambient sky as compared to the direct-nailed asphalt shingle roof (Fig. 13). The effect is due in part to the venting occuring on the tile's underside and in part to the thermal mass of the tile. Parker, Sonne, and Sherwin (2002) showed that a white galvanized metal roof slightly outperformed a white S-shaped cement tile roof because the thermal mass of the tile retained more heat that the air-conditioner had to temper earlier in the day than the house with a painted metal roof. However, in more moderate climates, this thermal mass effect is a benefit and will be discussed in the next section on heating seasonal performance.

It is difficult to judge whether venting or surface reflectance is the predominant force dropping the roof flux. However, Beal and Chandra (1995) showed that S-Mission tile on battens reduced the heat penetrating the ceiling by an additional $11 \%$ as compared to the same tile of the same color direct-nailed to the deck. Subsequently, sub-tile venting of the tile roofs appears just as important as is the boost in solar reflectance for reducing the heat gain into the attic and conditioned space. 


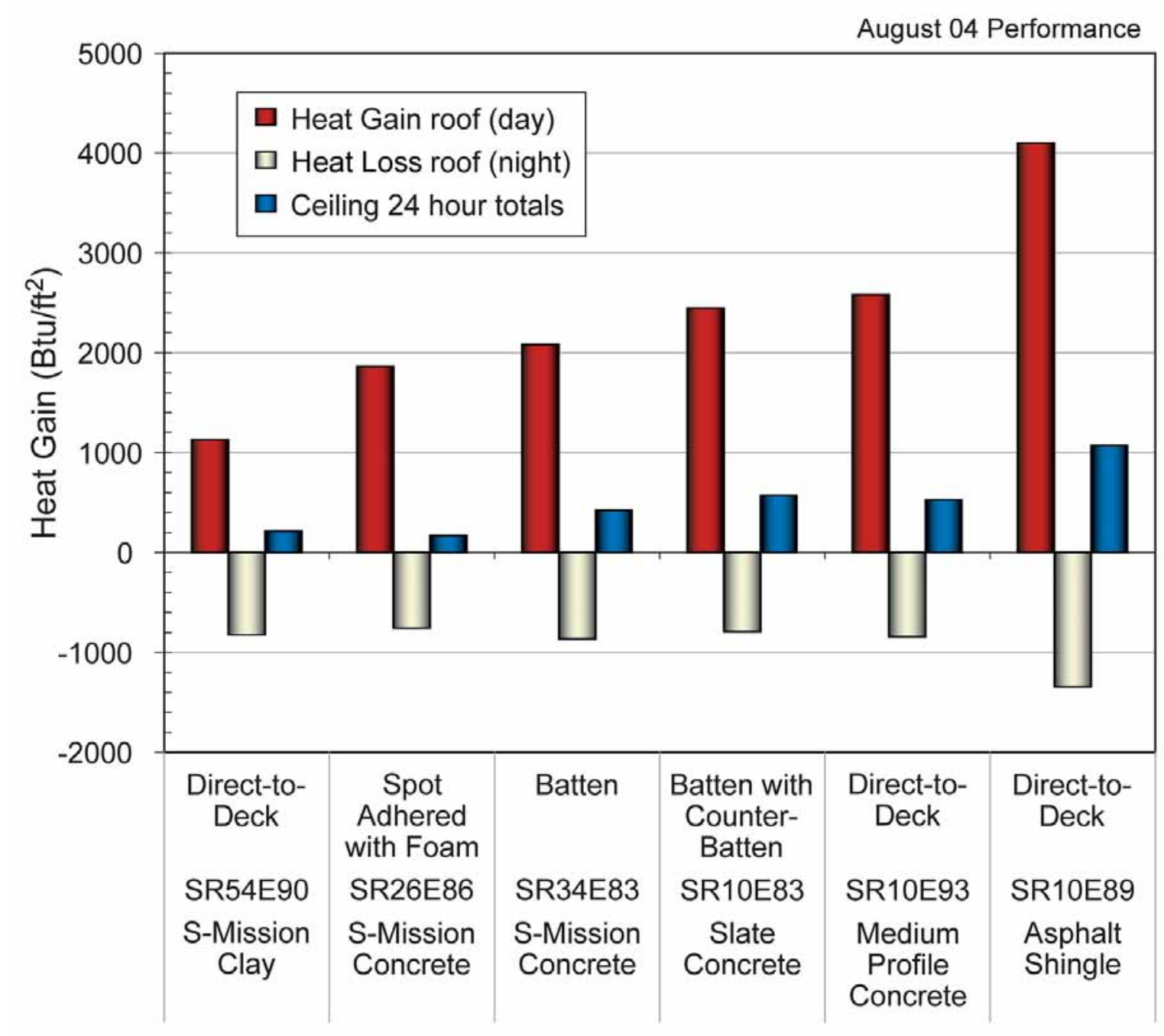

Fig. 13. S-Mission tile reduced the integrated daytime roof heat gain by 50 to $75 \%$ of the gain for the asphalt shingle roof.

\section{Effects of Opening the Ridge Vent}

As early as 1942, the Federal Housing Administration (FHA) set a 1:300 requirement (i.e., area of soffitt and ridge vent openings to attic footprint) for convective cooling of the attic air and for minimizing condensation on the underside of the roof sheathing as a preventative maintenance measure (FHA 1942). However, the importance of convection cooling of the attic air is controversial. The ridge vents for the tile and asphalt shingle roofs were opened for the summer of 2005 to observe the effects of attic ventilation and, more importantly, the effect of unrestricted airflow within the inclined air gap made by the underside of the tile roofs. Two summer days with very similar outdoor air temperatures and solar irradiance were selected. On one day, the ridge vent was closed; on the other day, it was kept open (Fig. 14). The soffitt vent was open for both summer days of field-testing.

Opening the ridge vent reduced the bulk air temperature within the inclined air channel for the slate (SR10E83) tile and also for the clay (SR54E90) tile (Fig. 14). At solar noon, the bulk air temperature near the underside of the slate tile was $10^{\circ} \mathrm{F}$ cooler than that observed for the same slate tile with the ridge vent closed during the previous summer. The effect for the S-Mission clay was about a $5^{\circ} \mathrm{F}$ drop in the bulk air temperature for the two different summer days with very similar weather. Slate tile are laid one atop 

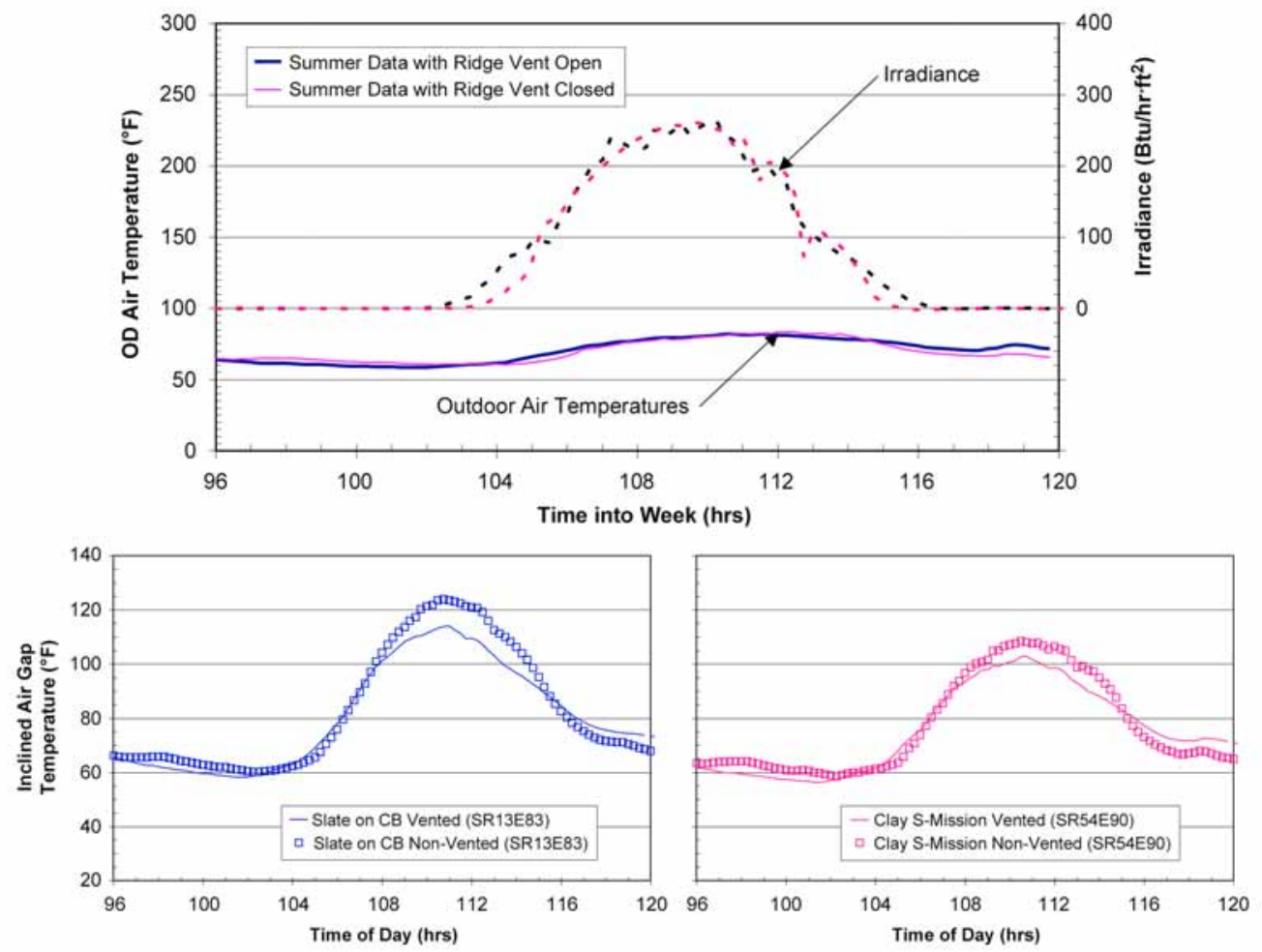

Fig. 14. Bulk air temperatures underneath the S-Mission clay and the concrete slate tile for two different summer days, one with the ridge vent open and the other with the ridge vent closed.

another and have little clearance for the seepage of air between overlapped tile. The S-Mission tile are designed to be porous to minimize wind uplift forces (Fig. 4). Therefore, the clay tile allowed more leakage of air by naturally induced thermal gradiants between overlapped tiles than observed for the slate tile system. As a result, opening the ridge vent caused a more significant drop in heat flow crossing the roof deck for the slate tile roof than for the clay tile roof (Fig. 15). The results imply that opening the ridge caused more heat to be exhausted out the ridge for both the S-Mission clay and the slate tile systems.

\section{Heating Season Field Performance}

Cool roofs have received much positive trade press, as well as some state and federal support for installation where comfort cooling is the dominant building energy load. In mixed climates with both significant heating and cooling loads, the wintertime effect reduces the energy benefit because the desirable roof heat gain in winter is diminished somewhat by the higher solar reflectance of the roof. The Achilles' heel of all cool roof systems is therefore the heating penalty that offsets the energy and cost savings associated with the cooling benefit of the reflective roof system. The colder the climate the greater is the penalty, and the trade-off between climate and reflective roofs limits their penetration into predominantly heating-load climates. However, field data for the tile roofs tested in East Tennessee's climate are showing that the tile's mass and sub-tile venting are negating the heating penalty associated with cool roofs. 

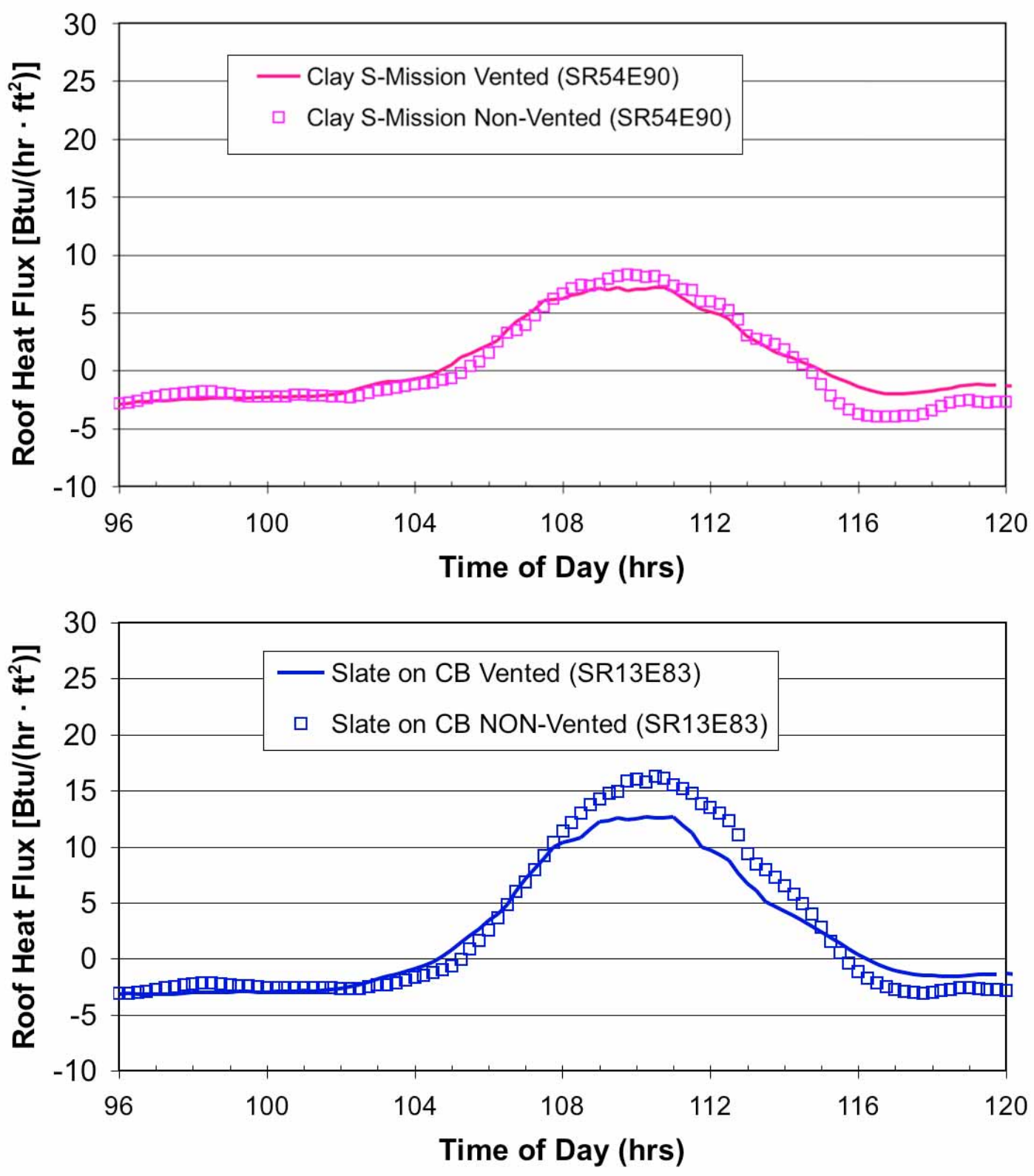

Fig. 15. Heat penetrating through the roof deck of the S-Mission clay tile and the concrete slate tile with and without venting of the roof deck.

Results from two consecutive days with clear Janurary skies are displayed in Fig. 16 to review the thermal performance of the clay and concrete tile roofs compared to that of the dark heat-absorbing asphalt shingle roof. The ridge vents for these tests were closed, and the average ambient air temperature for these two Janurary days was $32^{\circ} \mathrm{F}$. At solar noon, the roof deck of the attic with asphalt shingles (SR10E89) absorbed about $15 \mathrm{Btu} / \mathrm{h} / \mathrm{ft}^{2}$ of solar flux, which is almost twice that absorbed by the medium profile (SR10E93) or slate (SR13E83) roofs. The attic assemblies with S-Mission clay and concrete tile 


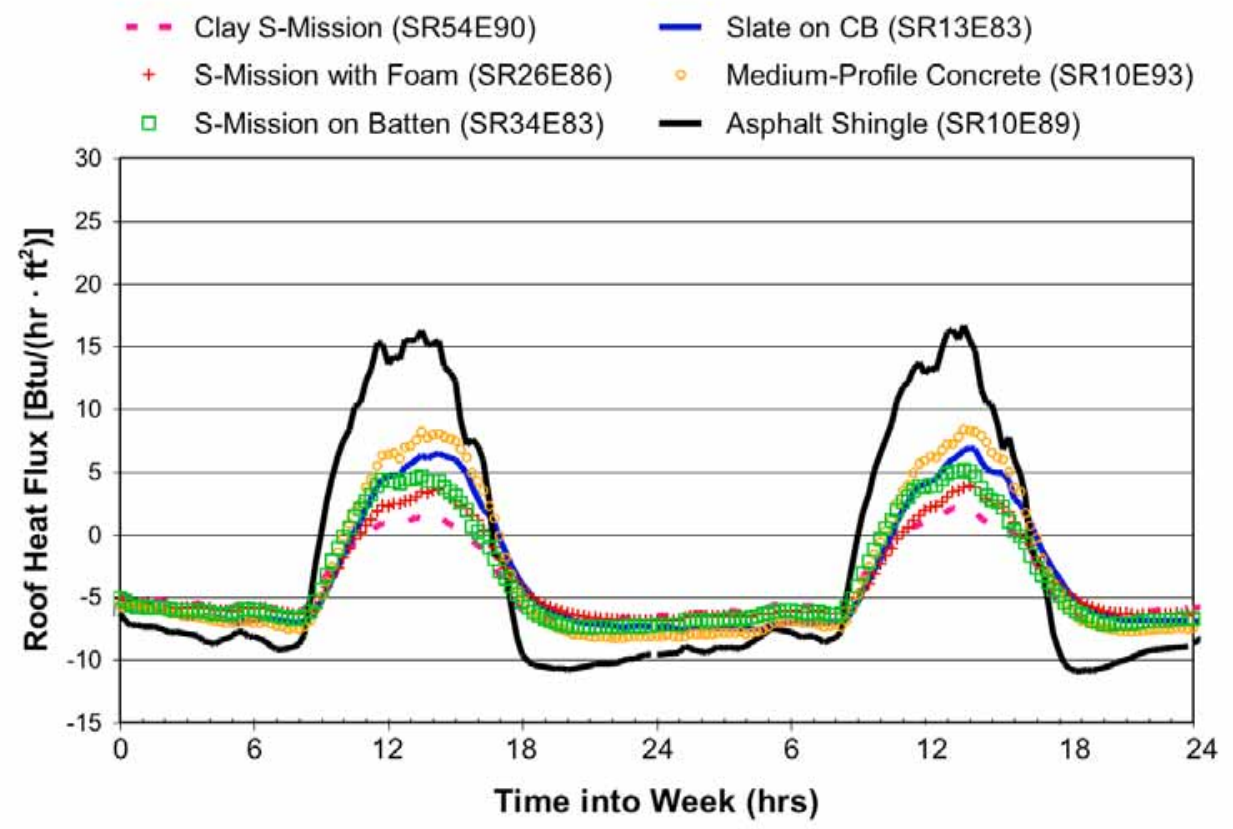

Fig. 16. Roof deck heat flow for two consecutive days in January 2005; the ridge vent is closed.

showed marginal heat gains, with the clay tile showing almost no gain even at solar noon. However, during the evening hours from about 8 p.m. through about 6 a.m., all the tile roofs lose less heat to the night sky than does the asphalt shingle roof (Fig. 16). The tile reach peak day temperatures ranging from $92^{\circ} \mathrm{F}$ for the SR34E83 S-Mission concrete to $75^{\circ} \mathrm{F}$ for the S-Mission clay tile (SR54E90). The shingle reaches about $105^{\circ} \mathrm{F}$ peak temperature. But during the night, the tiles are all warmer than the shingles because of the thermal mass of the tile and because the air channel formed on the underside of the tile adds an additional radiative resistance to night-sky radiations losses as compared to the direct nailed shingle.

\section{Thermal Mass Effects}

Results integrated over the month of Janurary 2005, as done similarly for August 2004, show that the thermal mass of the tile roofs nearly counterbalances the heating penalty associated with cool roofing for the moderate climate of Tennessee (Fig. 17). Again, venting the underside of the tile plays a part in the results. The asphalt shingle roof gains about $1000 \mathrm{Btu} / \mathrm{ft}^{2}$ of roof deck during all January days, while the tile roofs show little gain and some a loss of heat from the roof deck. However, during the evening hours the thermal mass and possibly the tile's air channel have reduced the heat loss from the roof to the point that the heat loss from the ceiling of all roofs is about the same (see blue bars in Fig. 17). These data are very promising, because the tile roofs are negating the heating penalty associated with a cool roof in Tennessee's moderate climate having $3662 \mathrm{HDD}_{65}$ and $1366 \mathrm{CDD}_{65}$. The fact that the SR54E90 and SR26E86 tile roofs actaully lost heat during the January days implies that the radiative resistance afforded by the inclined air gap on the tile's underside is the primary driver causing the reduction in nighttime heat losses. 


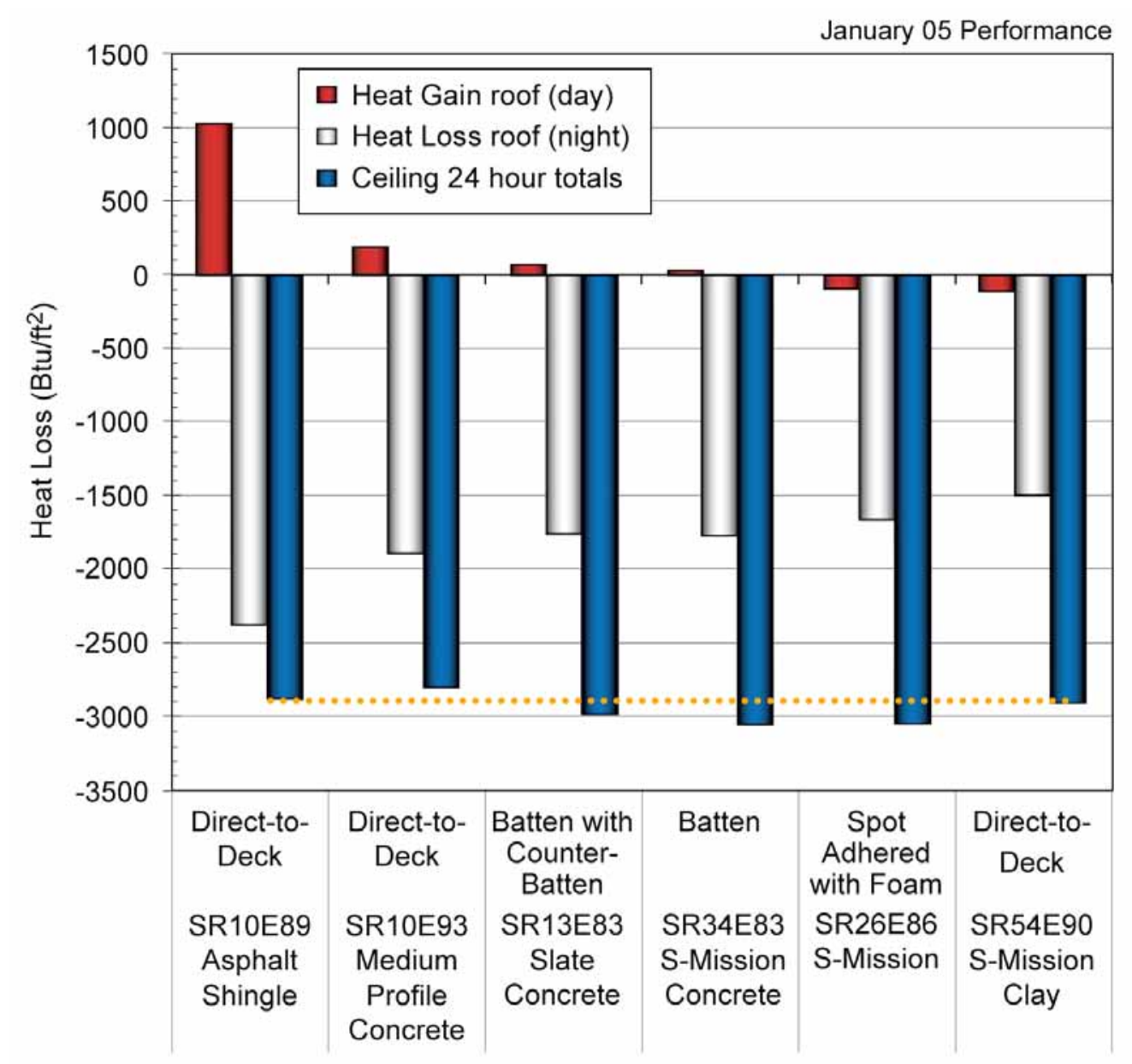

Fig. 17. Integrated heat flow measured through the roof deck for all tile and shingle roofs during the month of January 2005.

\section{Venting the Underside of Tile Roofs}

The transfer of heat across the roof tile and roof deck has similar physics to the problem associated with the heat transfer across the inclined air channel formed by roof-mounted solar collectors. Comprehensive reviews of both experimental and theoretical results are available in the literature. Hollands et al. (1976), Arnold et al. (1976), and most recently Brinkworth (2000) studied this situation as applied to flat-plate photovoltaic cladding.

All residential roofs are sloped and make an angle $\theta$ with the horizontal plane that ranges from $2 \mathrm{in}$. of rise per 12 in. of run ( $9.5^{\circ}$ slope) to a steep-sloped roof of $45^{\circ}$. During winter exposure, a roof deck is warmer than the tile and in the inclined air channel, the heated surface is positioned below the cooler tile surface much like the solar panel application studied by Hollands et al. (1976). Here, a more dense air layer near the tile overlays a lighter air adjacent to the roof deck (see $\theta=0$, Fig. 18). Hollands observed that the heat transfer across the air channel can switch from conduction to single-cell convection to Bénard cell convection, depending on the strength of a non-dimensional parameter called the Rayleigh (Ra) Number. For Rayleigh numbers less than $1708 / \operatorname{COS}(\theta)$, there is no naturally induced airflow within the cavity, and the heat transfer occurs exclusively by conduction. However, a flow of air occurs if buoyancy forces overcome the resistance imposed by the viscous or frictional forces. As the flow increases due to buoyancy, the heat transfer within the channel can switch to Bénard cell convection, 


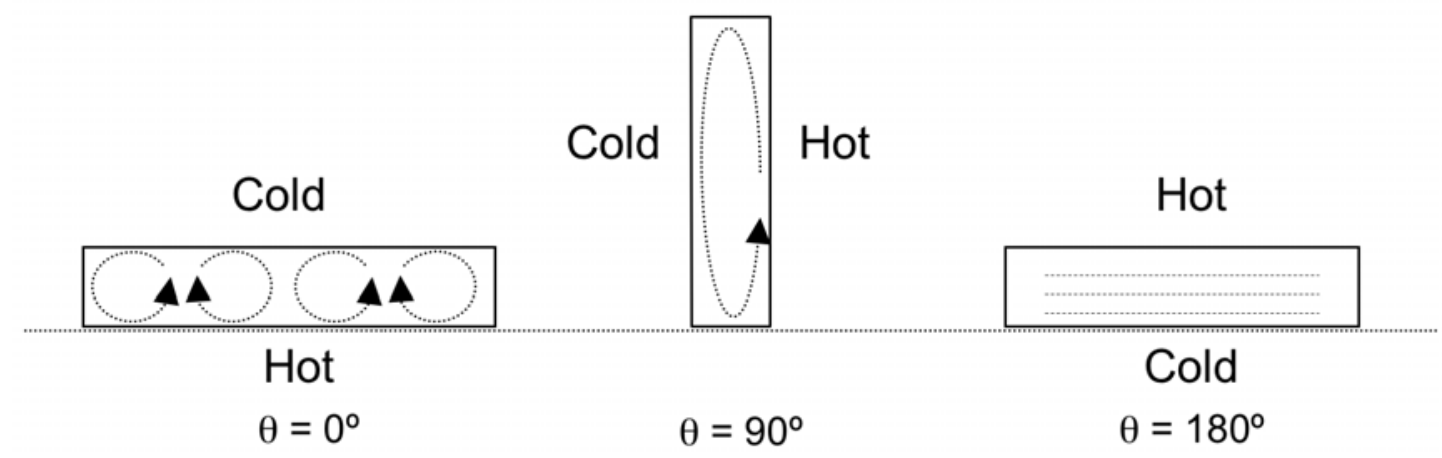

\section{Bénard convection}

Conduction dominate

Fig. 18. Heat transfer phenomena occurring on the underside of roof tile.

which has hexagonal cells with flow ascending in the center and descending along the sides of the air channel (see $\theta=0$, Fig. 18).

Arnold et al. (1976) observed that the channel's aspect ratio and the slope of the solar panel (for our application, a roof) had a major impact on the flow and heat transfer within the air channel. They observed that if the channel was rotated from $\theta=180^{\circ}$ (summer exposure for a roof) all the way to $\theta=0^{\circ}$ (winter exposure), the heat transfer rises to a maximum at $\theta=90^{\circ}$ and then, as $\theta$ decreases below $90^{\circ}$, the heat transfer rate first decreases and passes through a local minimum at $\theta^{*}$ (Bejan 1984). However, as $\theta$ decreases below $\theta^{*}$, the heat transfer rate again rises because of the inception of Bénard cell convection. Arnold et al. (1976) also observed that the aspect ratio of the channel changed the critical angle $\theta^{*}$ where the heat transfer across the channel was minimal. The information may be very useful for designing tile to limit ice damming in predominantly cold climates.

During summer exposure, the tile is hotter than the roof deck, and Bénard cell convection does not occur within the inclined channel because the lighter air layer is now atop the denser air layer near the roof deck. The air heated by the underside of the tile tends to rise, and natural convection begins within a boundary layer formed along the underside of the tile $(\theta=180$, Fig. 18). Brinkworth (2000) studied this situation as applied to flat-plate photovoltaic cladding, and it is this configuration and heat transfer mechanism that are evident in the field experiments discussed for the tile roof systems field-tested on the ESRA.

\section{Thermally Induced Airflow Rates}

An integral technique was used to formulate closed form solutions for the thermal boundary layer, the velocity profile and the heat transfer coefficient for the case of natural convection occurring in the inclined channel. Solving the momentum and energy equations for a constant solar flux yielded the following expression for the thermal boundary layer forming on the underside of a tile roof:

$$
\delta_{\mathrm{T}}=\frac{(288)^{1 / 5}}{\operatorname{Pr}^{2 / 5}}\left[\frac{\{1+5 / 4 \operatorname{Pr}\}^{1 / 5}}{\left\{\frac{g \beta q_{\text {Tile }} \operatorname{SIN}(\theta)}{k \cdot v^{2}}\right\}^{1 / 5}}\right] x^{1 / 5}
$$


The velocity profile for the thermally induced air movement in the channel becomes:

$$
\mathrm{U}(\mathrm{x}, \mathrm{y})=\mathrm{A}(\mathrm{x})\left\{\eta(1-\eta)^{2}\right\}
$$

and the temperature profile for the channel having a constant roof flux becomes:

$$
\mathrm{T}(\mathrm{x}, \mathrm{y})-\mathrm{T}_{\infty}=\frac{\mathrm{q}_{\text {roof }} \delta_{\mathrm{T}}}{2 \mathrm{k}_{\text {air }}}\left\{1-2 \eta_{\mathrm{T}}+\eta_{\mathrm{T}}^{2}\right\}
$$

where

$$
\begin{aligned}
A(x) & =\frac{g \beta\left\{T_{\text {Roof }}(x)-T_{\infty}\right\} \delta_{T} \operatorname{SIN}(\theta)}{4 v} \\
\eta & =y / \delta \\
\eta_{T} & =y / \delta_{T}
\end{aligned}
$$

The heat transfer coefficient can be determined by taking the temperature profile within the boundary layer and evaluating its gradient at the underside of the tile. Equating the convection to the conduction at the tile's underside yields the expression:

$$
\mathrm{h}_{\mathrm{x}}=\frac{2 \mathrm{k}_{\text {air }}}{\delta_{\mathrm{T}}}
$$

The expressions in Eqs. 2, 3, 4 and 5 are useful for estimating ballpark values for the bulk velocity and heat transfer coefficient within the air channel. After $14 \mathrm{ft}$ of run from the soffitt toward the ridge, the thermal boundary layer has grown to about $0.14 \mathrm{ft}$. Within this boundary layer the air's maximum velocity is about $1.8 \mathrm{ft} / \mathrm{s}$, and its average velocity is slightly less than $0.8 \mathrm{ft} / \mathrm{s}$. The local heat transfer coefficient is of the order $0.23 \mathrm{Btu} / \mathrm{h} /{ }^{\circ} \mathrm{F} / \mathrm{ft}^{2}$ of tile. These data helped validate bulk velocities obtained from tracer gas measurements; however, the expressions do not account for the obstructions evident in batten and counter-batten roof constructions.

\section{Numerical Simulations}

Computer simulations for thermally induced airflow and heat transfer across an inclined air channel were conducted for several different constant-temperature wall boundary conditions and several different inclinations with the horizontal plane to better understand the strength of natural convection forces occurring within the heated channel. The channel was modeled with and without obstructions (battens) on the top plate. The bottom and the two side surfaces of the channel were held at $68^{\circ} \mathrm{F}$, and the top surface was fixed at the higher temperature of $98^{\circ} \mathrm{F}$ to simulate summer exposure of the tile roof. The aspect ratio of the duct was fixed at 0.01 , and the inclination was $30^{\circ}$ from horizontal ( 5 in. of rise per 12 in. of run).

The numerical simulations in Fig. 19 are plotted in terms of the isotherms (constant temperature lines shown in color) and the streamlines (lines of constant velocity). The results depicted in Fig. 19a show that with no obstruction a natural convection flow occurs along the underside of the top plate. An exit jet is seen in line with the duct axis indicating a momentum of flow within the boundary layer that carries heat away from the roof deck. In Fig. 19b the obstruction (batten) forces the air to move down and around the batten, causing some mixing of air outside the established boundary layer of the smooth surface. The streamlines of constant velocity are observed penetrating almost to the bottom plate because of the obstructions. The typical gap in a batten and counter-batten slate roof is about 1.5 to 3 in., depending on 


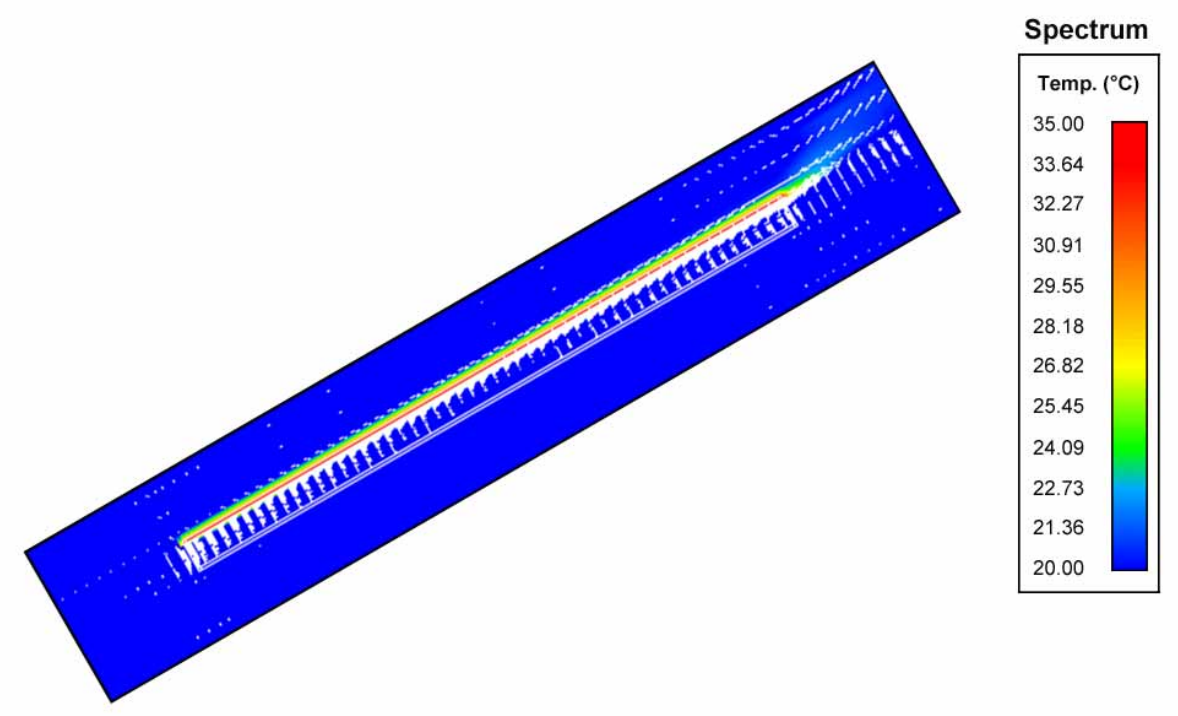

(a) No battens in channel

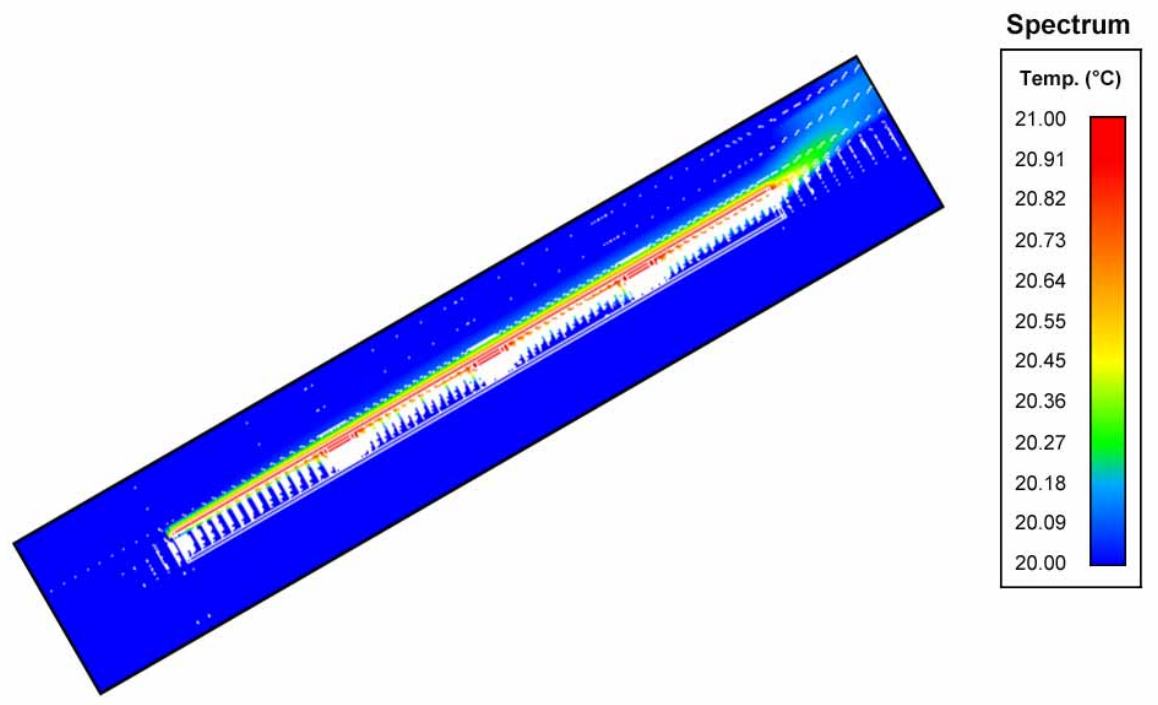

(b) Battens present in channel

Fig. 19. Numerical simulations for channel flow with and without battens fastened to the underside of tile (the top plate). The channel is at an incline of $30^{\circ}$ (5-in. rise for every 12 in. of run), and the top plate is $30^{\circ} \mathrm{F}$ warmer than the bottom plate.

the cross-sectional size of the battens. Recall from the boundary layer (Eq. 2) that after $14 \mathrm{ft}$ from soffitt to ridge, the boundary layer had grown to about $1.4 \mathrm{in}$. Figure $19 \mathrm{~b}$ implies that a fully developed flow is established within a shorter distance than occurs in a smooth channel (Fig. 19a). The result is very similar to the stocking of a fireplace. The air in the chimney initially is cold, and the hot air coming from the fire must develop a boundary layer through the colder chimney air to establish a positive pressure gradient for exhausting the hotter air. The inclined channel with battens forms a more developed flow in a shorter distance (i.e., boundary layers on the top and bottom plates meet in a shorter length of run) and a chimney effect occurs, fueling the removal of heat from the roof deck. Hence, the numerical results help to show 
qualitatively that the sub-tile venting can be very significant for dissipating heat away from the roof deck, making the tile roof system cooler than conventional direct-nailed systems.

The numerical results do not take into account the effect of a forced-flow component, which may aid or oppose the naturally induced flow, nor is air leakage between the tile overlaps considered. Mixed convection (forced convection driven by wind effects that are accompanied by buoyancy effects) is an additional confounding variable that must be mathematically described a priori the prediction of the heat transfer across the roof deck. The key to the problem is to predict accurately the airflow within the cavity. Once known, the portions of heat penetrating the roof deck and that convected away through the ridge vent can be derived from energy balances.

\section{Airflow Measurements Using Tracer Gas}

Measurements were made of the airflow underneath the clay and concrete tile roofs as the buoyancydriven flow traveled from the soffitt to the ridge of each tile roof. We designed a procedure using tracer gas techniques outlined in ASTM E 741 and also by Lagus et al. (1988). The procedure required monitoring the decay rate of the tracer gas $\mathrm{CO}_{2}$ with time using the following equation derived from a continuity balance for the concentration of $\mathrm{CO}_{2}$ :

$$
\dot{\mathrm{V}}_{\text {Air }}=-\frac{\mathrm{V}_{\text {channel }}}{\mathrm{t}} \mathrm{LN}\left[\frac{\mathrm{C}(\mathrm{t})-\mathrm{C}_{\infty}}{\mathrm{C}_{\mathrm{i}}-\mathrm{C}_{\infty}}\right]
$$

Three carbon dioxide monitors were placed inside each attic space, and sampling tubes were inserted into the inclined channel from the underside of the OSB decking. The monitors sampled the gas concentration near the soffitt, at the center of the roof and within $2 \mathrm{ft}$ of the ridge vent. We injected the gas into the vent gap of the soffitt and literally saturated the cavity with about $20,000 \mathrm{ppmv}$ of $\mathrm{CO}_{2}$ gas. The polytropic throttling process occurring during the injection of $\mathrm{CO}_{2}$ from a pressurized cylinder (i.e., the gas throttles from about 2000 to $20 \mathrm{psi}$ ) required the gas to be artificially heated to about $110^{\circ} \mathrm{F}$ before being injected into the vent cavity. After a substantial buildup of concentration registered on each monitor (i.e., 20,000 ppmv of $\mathrm{CO}_{2}$ ) the gas injection was stopped and concentration was recorded at timed intervals (Fig. 20).

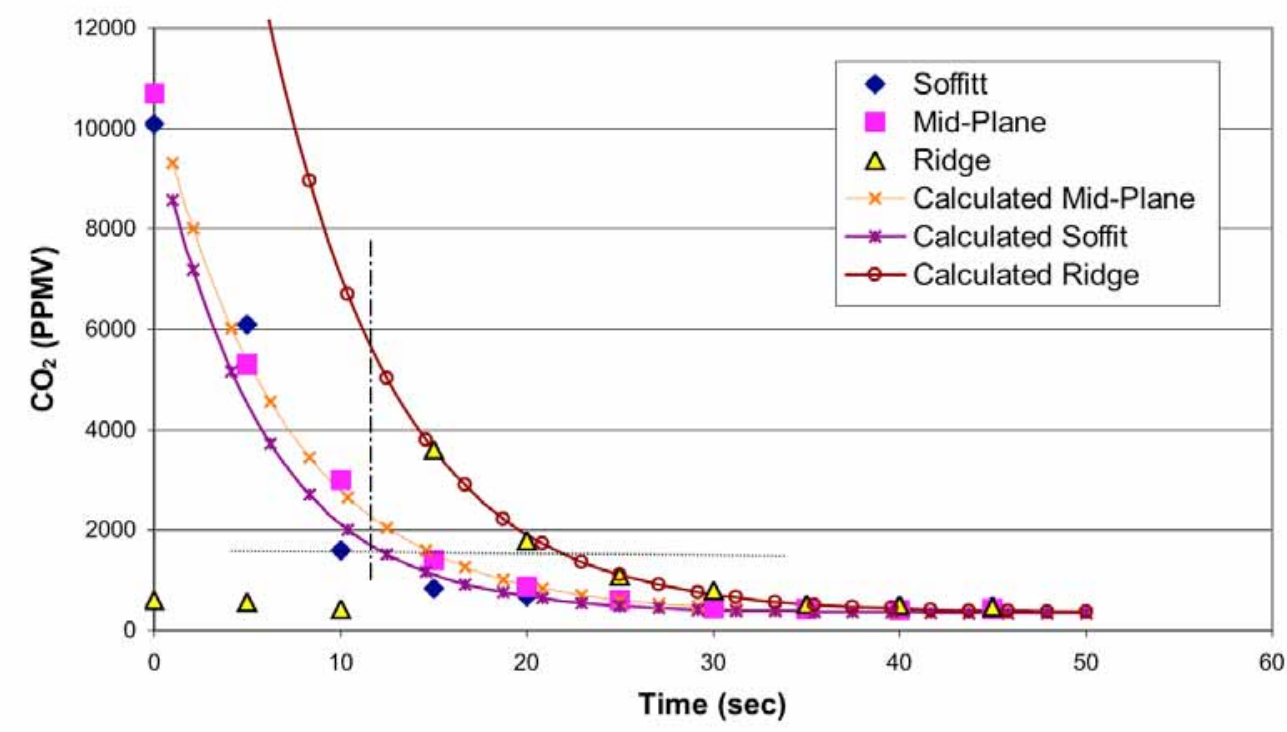

Fig. 20. Concentration of $\mathrm{CO}_{2}$ measured under the slate tile roof with batten and counter-battens. 
Data for the five vented clay and concrete tile roofs were collected (Table 2) and the calculated airflows ranged from about 12 to $33 \mathrm{cfm}$. The average velocity ranged from about 0.4 to $0.9 \mathrm{ft} / \mathrm{s}$, which is consistent with the average velocity calculated from boundary layer theory.

Table 2. Airflow rate and bulk velocity measured at the center of each attic assembly and under the clay and concrete tile roofs using $\mathrm{CO}_{2}$ as a tracer gas.

\begin{tabular}{|r|c|c|c|c|}
\hline & & & \\
& S-Mission & Medium Profile & S-Mission with foam & Slate on Counter Batten S-Mission on Batten \\
\cline { 2 - 6 } & Clay & & \multicolumn{2}{c|}{ Concrete Tile } \\
\hline Volume $\left(V_{\text {Channel }}\right.$ in $\left.^{3}\right)$ & 7045.1 & 5600.0 & 4444.8 & 5433.1 \\
\hline Airflow $(\mathrm{cfm})$ & 32.9 & 11.9 & 15.5 & 19.3 \\
\hline Average Velocity $\left(V_{\text {air }} \mathrm{ft} / \mathrm{s}\right)$ & 0.88 & 0.40 & 0.66 & 0.67 \\
\hline
\end{tabular}

All measurements were made around solar noon when the roofs had their highest respective roof temperatures and highest heat flows penetrating into the attic. The clay tile yielded the highest measured buoyancy induced airflow, which is very interesting because the combination of its solar reflectance and sub-tile venting are believed to be the drivers causing the $\approx 70 \%$ reduction in deck heat flow as compared to a direct-nailed shingle roof.

\section{Air Leakage from Tile Systems}

Most roof tiles are designed with a gap between the overlapping of tiles placed on the roof. The design equalizes the static air pressure and reduces wind uplift for oceanfront locations occasionally threatened by hurricanes. Kehrer (2005) conducted wind washing studies for tile roofs field tested in Europe during the winter. He observed that the roof pitch facing windward incurred 6-26\% more heat loss than the leeward-pitched roof at wind velocities of about $6.7 \mathrm{mph}$. Using tracer gas experiments Kehrer confirmed that wind washing or the intrusion of outdoor ambient air into the inclined air channel occurs and causes the increased heat loss for windward-facing tile roofs.

Kehrer's (2005) field experiments provide the only open literature data known to the authors that describe the effect of wind washing on the thermal performance of tile roofs. Results from tracer gas testing at ORNL were reduced to leakage rates digressing and egressing the tile roofs in support of modeling and predicting the heat transfer across the tile roof. Data for the S-Mission clay and the slate concrete tiles are listed in Table 3 with measures of airflows near the soffitt and near the ridge from which leakage rates can be viewed for the two styles of tile.

Table 3. Air infiltration and exfiltration from the S-Mission clay (SR54E90) and the slate concrete (SR13E83) tile roof systems.

\begin{tabular}{|c|c|c|c|c|c|c|c|c|}
\hline Tile System & $\begin{array}{c}\text { OD Air } \\
\text { Temperature }\end{array}$ & Wind Direction & Wind Speed & $\begin{array}{c}\text { Solar Irradiance } \\
\text { Horizontal }\end{array}$ & $\begin{array}{c}\text { Air Gap } \\
\text { Temperature } \\
\end{array}$ & Soffitt & Near Ridge & $\begin{array}{c}\text { Air Exfiltration (+) } \\
\text { Air Infiltration (-) } \\
\end{array}$ \\
\hline & ${ }^{\circ} \mathrm{F}$ & North $=0^{\circ}(\mathrm{CW}+)$ & $\mathrm{mph}$ & Btu/hr $\cdot \mathrm{ft}^{2}$ & ${ }^{\circ} \mathrm{F}$ & $\mathrm{cfm}$ & $\mathrm{cfm}$ & $\mathrm{cfm}$ \\
\hline \multirow[t]{4}{*}{ S-Mission Clay } & 93.6 & 175.7 & 1.57 & 214.3 & 111.8 & 52.6 & 27.3 & 25.31 \\
\hline & 92.3 & 190.1 & 1.63 & 262.9 & 118.0 & 58.4 & 36.5 & 21.97 \\
\hline & 93.7 & 187.0 & 1.13 & 234.4 & 118.0 & 35.3 & 19.5 & 15.75 \\
\hline & 90.9 & 255.3 & 1.42 & 216.8 & 104.1 & 28.5 & 34.7 & -6.20 \\
\hline & & & & & & & & \\
\hline \multirow[t]{2}{*}{ Slate Concrete } & 92.0 & 113.1 & 1.49 & 237.6 & 127.1 & 32.1 & 25.5 & 6.52 \\
\hline & 91.8 & 202.1 & 1.97 & 276.6 & 128.8 & 22.7 & 19.5 & 3.23 \\
\hline
\end{tabular}

The S-Mission clay tile are designed to be more porous than the slate tile and have a greater leakage of air (Table 3). Also, the cross-sectional area on the underside of the clay tile is slightly larger than that of the 
slate tile, being 89.5 in. $^{2}$ versus 69 in. $^{2}$ for the slate. Therefore, a slightly larger airflow occurs under the clay tile as compared to the slate tile, even though the underside air temperature is hotter for the slate. The hotter the air temperature, the greater the bouyancy and induced air movement.

The air exfiltration from the clay tile appears to correlate somewhat with wind direction (Fig. 21). Peavy (1979) saw that the air exchange rate for attics correlated with the wind strength and direction incident on the soffitts. Table 3 data for wind direction show the leeward-directed winds possibly reduced the air pressure above the tile while the one more windward point $\left(255.3^{\circ}\right.$ for clay) may cause an inleakage of air into the tile. The slate tile does not appear as susceptible to wind effects simply because of its reduced porosity as compared to the S-Mission design (Fig. 21).

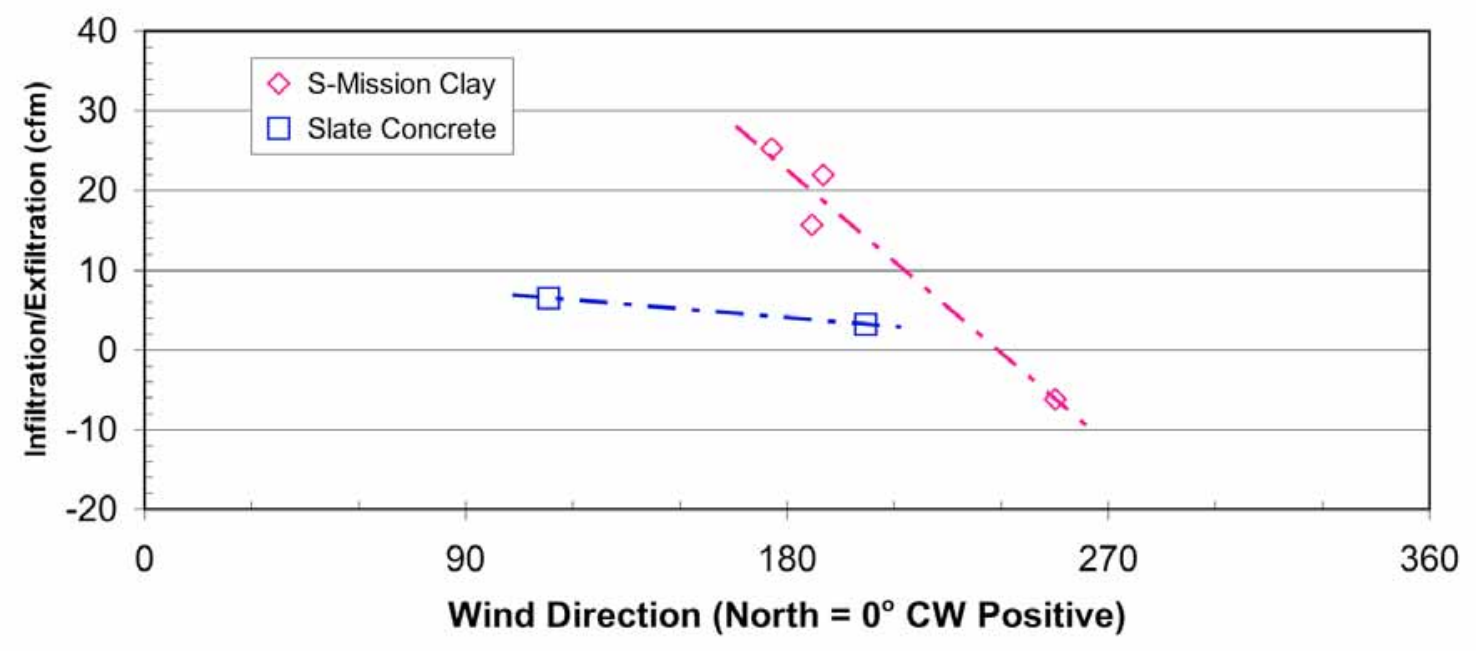

Fig. 21. The leakage of air from the underside of the slate and S-Mission clay tile roofs.

\section{ATTICSIM MODEL}

AtticSim is a computer tool for predicting the thermal performance of residential attics. It mathematically describes the conduction through the gables, eaves, roof deck, and ceiling; the convection at the exterior and interior surfaces; the radiosity heat exchange between surfaces within the attic enclosure; the heat transfer to the ventilation air stream; and the latent heat effects due to sorption and desorption of moisture at the wood surfaces. Solar reflectance, thermal emittance, and water vapor permeance of the sundry surfaces are input. The model can account for different insulation R-values and/or radiant barriers attached to the various attic surfaces. It also has an algorithm for predicting the effect of air-conditioning ducts placed in the attic (Petrie et al. 2004). The code reads the roof pitch, length, and width and the ridge orientation (azimuth angle with respect to north) and calculates the solar irradiance incident on the roof. Conduction heat transfer through the two roof decks, two gables, and vertical eaves are modeled using the thermal response factor technique (Kusuda 1969), which requires the thermal conductivity, specific heat, density, and thickness of each attic section for calculating conduction transfer functions.

Heat balances at the interior surfaces (facing the attic space) include the conduction, the radiation exchange with other surfaces, the convection, and the latent load contributions. Heat balances at the exterior surfaces balance the heat conducted through the attic surface to the heat convected to the air, the heat radiated to the surroundings, and the heat stored by the surface. Iterative solution of the simultaneous equations describing the heat balances yields the interior and exterior surface temperatures and the attic air temperature at 1-h time steps. The heat flows at the attic's ceiling, roof sections, gables, and eaves are calculated using the conduction-transfer function equations. The tool was validated by Wilkes (1991) 
against field experiments and is capable of predicting the ceiling heat flows integrated over time to within $10 \%$ of the field measurement.

\section{Attic Ventilation}

Sub-tile venting of tile roofs has been a primary focus of Task 2.6.3; however, modeling the ventilation of the attic is also important for predicting accurately the heat penetrating through the ceiling into the conditioned space. Miller et al. (2004) validated AtticSim's ability to predict reasonable values of attic ventilation against the data of Burch and Treado (1979) and by Walker (1993) and against the data of Parker, Fairey, and Gu (1991). Miller et al. (2004) assumed equal soffit and ridge vent openings with a net free vent area of 1:300.

The steep-slope attic assemblies, however, have shed-type roofs, and the ridge vent was closed for a summer followed by another summer of exposure with the ridge vent open. The code was exercised with and without the ridge vent open and the direct-nailed shingle roof modeled as a shed-type roof. The results show that soffitt and ridge venting (Fig. 22, + symbol for AtticSim prediction) resulted in too much air exchange within the attic cavity because AtticSim under predicted the attic air temperature measured at center of the cavity. The code was then run using measured temperatures for the roof and ceiling boundary conditions to eliminate the confounding variable of weather and enable a check of the attic's radiosity exchange and the air exchange rate. Soffitt venting (ridge modeled as nearly shut) yielded reasonable results (o symbol for AtticSim - BC), as seen in Fig. 22. The results show that a slight adjustment of AtticSim's ventilation algorithm yielded accurate attic air temperatures and ventilation rates.

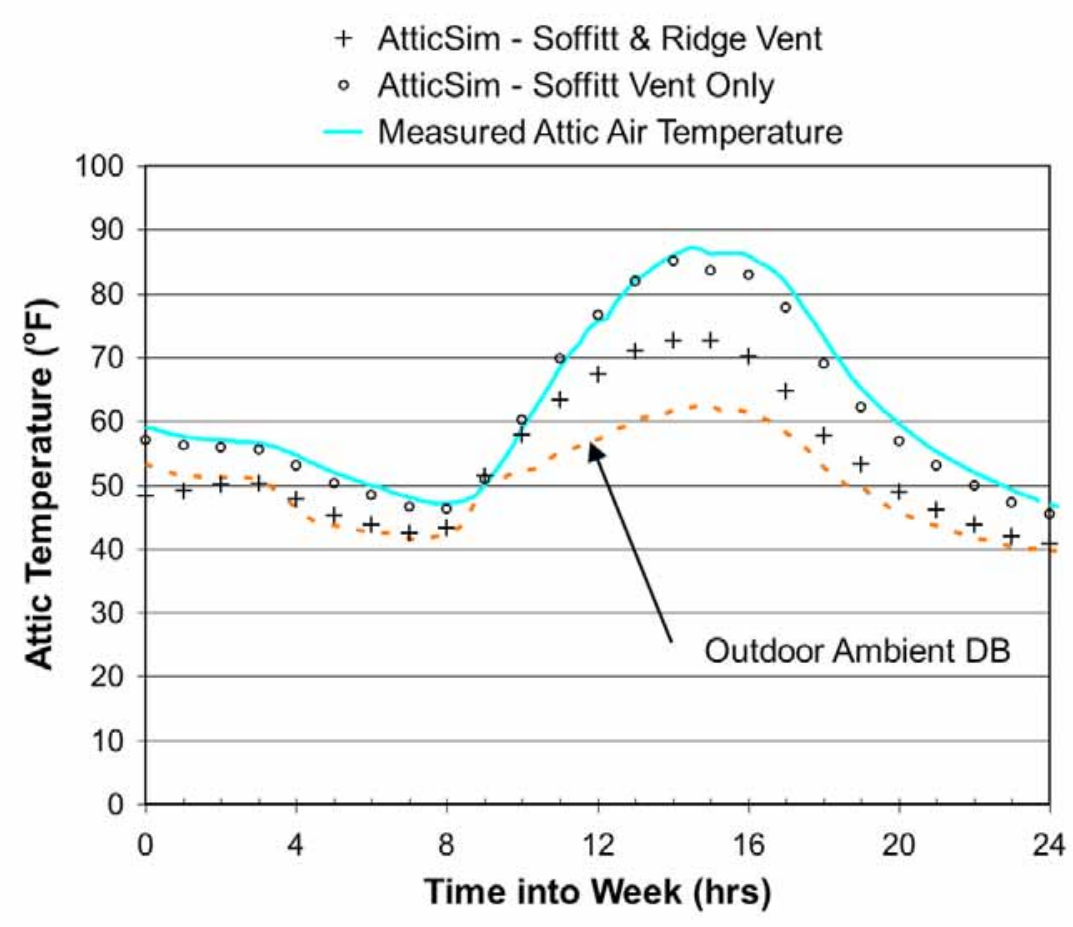

Fig. 22. AtticSim predicted the attic air temperature of the steep-slope attic assembly modeled as a shed roof with and without ridge venting of the shingle roof. 


\section{Validation Efforts}

Inputs to the AtticSim computer code were developed that describe the geometry and the thermal and moisture characteristics for the attic test lane having a roof with direct-nailed asphalt shingles (SR10E89). Conduction heat transfer through the south-facing roof deck was modeled by developing conductiontransfer functions for a shed roof and for the other five attic surfaces. The transfer functions predict the time-dependent one-dimensional conduction transfer at the interior and exterior surfaces of the attic and couple the results with radiation and convection heat transfer within the attic enclosure to predict the heat flux penetrating into the conditioned space. AtticSim did an excellent job of validating the heat flow penetrating throught the ceiling of the attic assembly having the the direct-nailed shingle roof (Fig. 23).

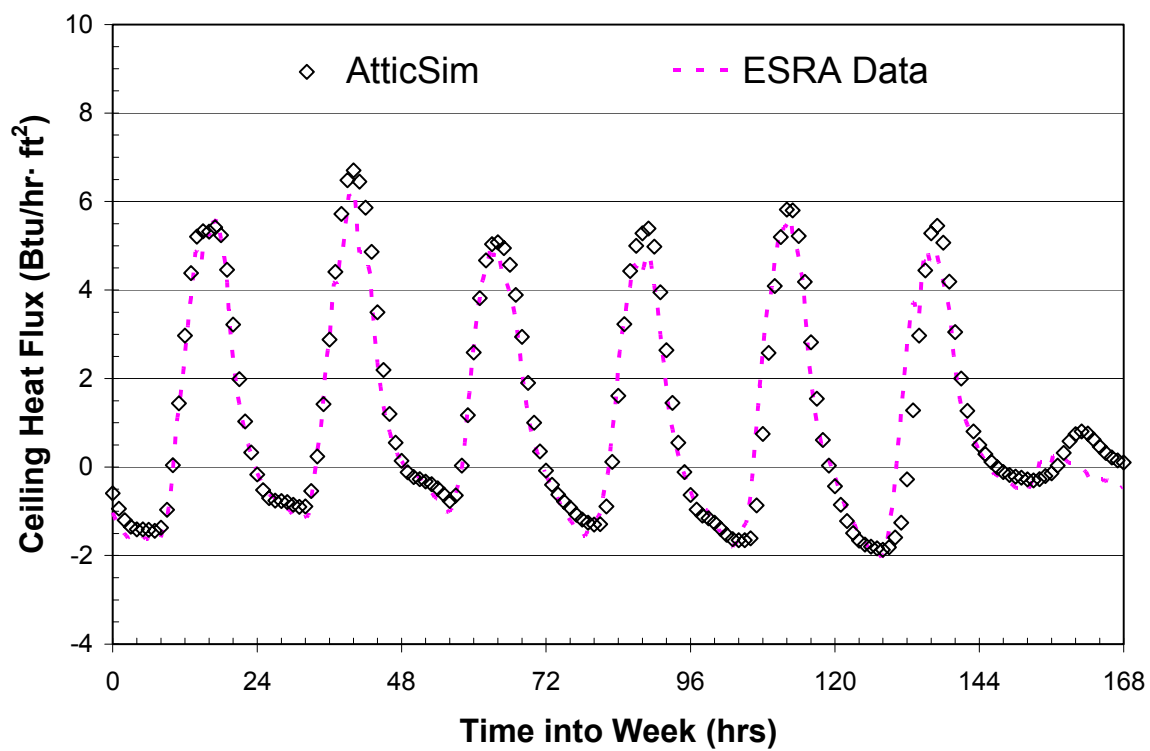

Fig. 23. Validation of AtticSim against field measures of the ceiling heat flux gleaned from the ESRA steep-slope roof assembly with a direct-nailed shingle roof.

The predicted heat flow tracks very well the heat flows measured at solar noon and also during the evening hours. AtticSim tended at solar noon to overpredict the surface temperature of the shingles (Fig. 24), and the heat flux penetrating the roof deck was therefore overpredicted at solar noon. However, the attic air temperature was underpredicted and compensated for the discrepency in Fig. 24 yielding the results shown in Fig. 23 for the ceiling heat flux. Despite these small inconsistencies, the code works well for the case of direct-nailed roof products.

Efforts are continuing to predict the heat flow across a tile roof having a venting occurring along the underside of the roof between the roof deck and the tile. The heat transfer correlations by McAdams (1954) and Nusselt's boundary layer theory were tested against the experimental data for the S-Mission clay and concrete slate tile roofs. McAdams's correlation is for immersed external free convection flows around a vertical isothermal plate and has the form:

$$
\overline{\mathrm{NU}}=\frac{\bar{\hbar} \mathrm{L}}{\mathrm{k}}=0.59\left(\mathrm{Ra}_{\mathrm{L}}\right)^{1 / 4}
$$




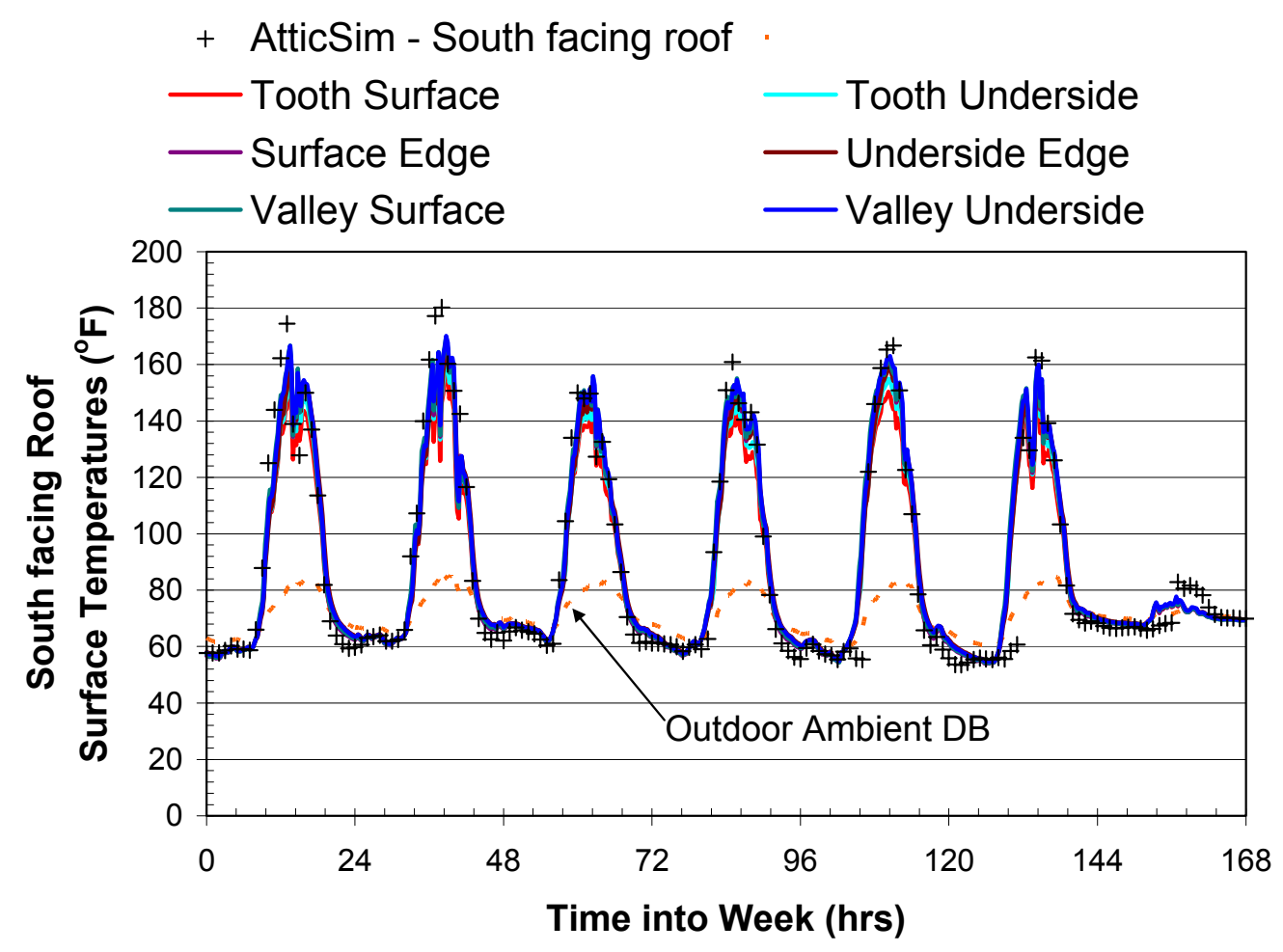

Fig. 24. Validation of AtticSim against field measures of the surface temperatures for the asphalt shingles gleaned from the ESRA steep-slope roof assembly.

The boundary layer correlation for a uniform heat flux has the form:

$$
\overline{\mathrm{NU}}=\frac{5}{(11520)^{1 / 5}}\left\{\frac{\operatorname{Pr} \cdot \operatorname{SIN}(\theta)}{4 / 5+\operatorname{Pr}}\right\}^{1 / 5}\left(\operatorname{Ra}^{*}\right) \mathrm{L}
$$

Equations 7 and 8 were used to back-calculate the mass flow rate of air moving up the inclined air channel. Energy balances for internal duct flow were derived using constant wall and constant heat flux boundary conditions, and the airflow in the enclosed channel was calculated using the measured temperature and heat flow field data for the five tile roof systems. Using a constant temperature boundary condition yields the expression:

$$
\mathrm{LN}\left[\frac{\mathrm{T}_{\text {Wall }}-\mathrm{T}_{\text {Air out }}}{\mathrm{T}_{\text {Wall }}-\mathrm{T}_{\text {Airin }}}\right]=-\frac{\hbar\{P \cdot L\}}{\dot{\mathrm{m}}\left(\mathrm{C}_{\mathrm{PAir}}\right)}
$$

while the constant flux condition yields the expression:

$$
\dot{\mathrm{m}} \cdot \mathrm{C}_{\mathrm{PAir}}\left(\mathrm{T}_{\text {Air out }}-\mathrm{T}_{\text {Air in }}\right)=\mathrm{q}_{\text {solar }}^{\prime \prime}(\mathrm{P} \cdot \mathrm{L})
$$

The constant surface temperature scenario [Eq(s). 7 and 9] yielded volumetric airflow rates of about 24 to $32 \mathrm{cfm}$. The constant heat flux condition [Eq(s). 8 and 10] yielded flow rates of about 40 to $80 \mathrm{cfm}$, which is high probably because we used the measured solar irradiance rather than the flux from the underside of 
the tile (not known from field data). These back-calculated airflow values are within reason of the airflows determined from the tracer gas experiments (Table 2).

\section{CONCLUSIONS}

Clay and concrete tile roofs are energy-efficient cool roof products as verified by field results obtained for East Tennessee's climate. The combination of improved solar reflectance afforded by CRCMs and subtile venting reduced the noontime heat flow crossing the roof deck of the clay tile roof by $70 \%$ of the flow crossing the conventional shingle roof, which in turn, reduced the heat entering the conditioned space by $60 \%$ of the heat flow penetrating the ceiling of the attic assembly with shingle roof. The slate and medium-profile concrete roofs, having nearly the same surface properties as the conventional shingle, reduced the deck heat flow $\sim 45 \%$ of that crossing the shingle roof because of sub-tile venting.

Proportioning the reduction in deck heat flows due to sub-tile venting to the reducton due to CRCMs and sub-tile venting indicates that sub-tile venting is equivalent to about 30 points of solar reflectance. In other words, the slate tile (SR13E83) on battens and counter-battens is equivalent to a direct-nailed slate roof system with solar reflectance of 0.43 and thermal emittance of 0.83 . The results imply that cool roof credits are obtainable for sub-tile venting; the effects of sub-tile venting and CRCMs are synergistic; and subsequently, sub-tile venting of a tile roof is just as important as is the boost in solar reflectance for reducing the heat gain into the conditioned space.

Opening the ridge vent of the attics to allow both attic and sub-tile ventilation caused more heat to be exhausted out the ridge for both the S-Mission clay and the slate tile systems and therefore further improved the performance of the two tile roofs. The effect was more pronounced for the slate tile than observed for the S-Mission tile because the slate tile has less air leakage between tiles.

Tracer gas experiments successfully measured the bouyancy-induced airflows observed for sub-tile venting. These airflows yielded bulk velocities that were within reason of values deduced from firstprinciple energy balances for the inclined air channel. The sub-tile venting of the S-Mission tile, being designed porous to alleviate wind uplift, was observed to be more susceptible to wind effects than was the slate tile roof.

Summer heat flows for the month of July 2005 were integrated over the daylight and nighttime hours to show seasonal performance of the various roof systems (Table 4). The ridge vent was open for attic and for sub-tile ventilation for all test roofs during July 2005. The best-performing roofs were the directnailed S-Mission clay tile and the S-Mission concrete tile spot adhered with foam. Both roofs caused a $50 \%$ reduction in the heat penetrating through the ceiling over the full July month. The maximum attic air temperatures for July show the attic of the conventional shingle roof is about 10 to $15^{\circ} \mathrm{F}$ warmer than any

Table 4. July 2005 attic temperatures and cumulative heat flows through the roof deck and ceiling of the attic

\begin{tabular}{|c|c|c|c|c|c|c|c|}
\hline \multirow{2}{*}{ Test } & \multirow[t]{2}{*}{ SR \& TE } & \multirow{2}{*}{$\begin{array}{c}\text { Roof Deck } \\
\text { Construction }\end{array}$} & \multicolumn{2}{|c|}{ Attic Air $\left({ }^{0} \mathrm{~F}\right)$} & \multicolumn{2}{|c|}{$\begin{array}{c}\text { Roof Deck Heat Flux } \\
\left.\text { (Btu/ft }{ }^{2}\right)\end{array}$} & \multirow{2}{*}{$\begin{array}{l}\text { Ceiling Heat } \\
\left.\text { Flux (Btu/ft }{ }^{2}\right) \\
24-\text { Hour }\end{array}$} \\
\hline & & & Average & $\operatorname{Max}$ & Daytime & Nighttime & \\
\hline Asphalt Shingle & SR10E89 & Direct-to-Deck & 88.7 & 116.4 & 44921 & -1085 & 1999 \\
\hline Slate Concrete & SR13E83 & atten \& Counter-batten & 84.8 & 106.4 & 2915 & -543 & 1366 \\
\hline S-Mission Concrete & SR34E83 & Batten & 83.7 & 103.6 & 2611 & -666 & 1351 \\
\hline Medium Profile Concrete & SR10E93 & Direct-to-Deck & 84.3 & 105.5 & 3172 & -522 & 1200 \\
\hline S-Mission Concrete & SR26E86 & Spot Adhered with Foam & 83.6 & 103.2 & 23 & -603 & 956 \\
\hline S-Mission Clay & SR54E90 & Direct-to-Deck & 83.3 & 101.6 & 1540 & -649 & 873 \\
\hline
\end{tabular}


of the other tile roofs because of the heat flow crossing the roof deck of the respective tile, which was 35 to $70 \%$ less than that crossing the shingle roof (Table 4 ).

During January 2005 winter exposure (Table 5), sub-tile venting has reduced the heat loss from the tile roofs to the point that it is less than the loss for the asphalt shingle roof. The tile roofs are negating the heating penalty associated with a cool roof in Tennessee's moderate climate having $3662 \mathrm{HDD}_{65}$ and $1366 \mathrm{CDD}_{65}$. The improved summer performance (Table 4) coupled with the reduced heat losses during the winter (Table 5) show that tile roofs can benefit from CRCMs while at the same time negate the heating penalty associated with a cool roof. Therefore sub-tile venting of tile roofs provides tile manufacturers the opportunity to market high IR reflective tile in more predominant heating load climates.

Table 5. January 2005 attic temperatures and cumulative heat flows through the roof deck and ceiling of the attic assemblies with the ridge closed to attic and sub-tile ventilation

\begin{tabular}{|c|c|c|c|c|c|c|c|}
\hline \multirow{3}{*}{$\begin{array}{l}\text { Test } \\
\text { Roof }\end{array}$} & \multirow{3}{*}{ SR \& TE } & \multirow{3}{*}{$\begin{array}{l}\text { Roof Deck } \\
\text { Construction }\end{array}$} & \multirow{2}{*}{\multicolumn{2}{|c|}{ Nighttime Attic Air $\left({ }^{\circ} \mathrm{F}\right)$}} & & & \\
\hline & & & & & \multicolumn{2}{|c|}{$\begin{array}{c}\text { Roof Deck Heat Flux } \\
\left(\text { Btuift }^{2}\right)\end{array}$} & \multirow{2}{*}{$\begin{array}{l}\text { Ceiling Heat } \\
\text { Flux } \text { (Btu/ft }^{2} \text { ) } \\
24-\text { Hour }\end{array}$} \\
\hline & & & Average & Min & Daytime & Nighttime & \\
\hline Medium Profile Concrete & SR10E93 & Direct-to-Deck & 52.8 & 31.9 & 185 & -1890 & -2803 \\
\hline Asphalt Shingle & SR10E89 & Direct-to-Deck & 49.9 & 25.6 & 1024 & -2376 & -2879 \\
\hline S-Mission Clay & SR54E90 & Direct-to-Deck & 46.7 & 25.5 & -110 & -1499 & -2906 \\
\hline Slate Concrete & SR13E83 & Batten \& Counter-batten & 52.5 & 31.4 & 69 & -1761 & -2983 \\
\hline S-Mission & SR26E86 & Spot Adhered with Foam & 51.1 & 29.5 & -94 & -1664 & -3054 \\
\hline S-Mission Concrete & SR34E83 & Batten & 50.1 & 26.0 & 30 & -1772 & -3055 \\
\hline
\end{tabular}

The inclined air channel formed by the tile and the roof deck provides an additional radiative resistance to night-sky heat losses from the tile as compared to the direct-nailed shingle roof. Two of the tile roofs, the clay tile and the S-Mission concrete tile roof spot-adhered to the deck have no net heat gain during the daylight hours for the January exposure (Table 5). Therefore, the reduction in night sky radiation is due more to the decoupling of conduction prevalent in the direct-nailed shingle roof rather than to the thermal mass of the concrete and clay tile roofs. The air channel forces the heat flow from the roof deck to radiate across the air channel rather than conduct from the roof deck through to the surface of the shingle roof.

\section{RECOMMENDATIONS}

It is believed that in the simplest case, with no bulk air velocity, the heat transfer within the roof air channel will be dominated by natural convection, but that the more likely case, given some appreciable value of bulk air velocity, will be mixed convection heat transfer. Understanding the regime of heat transfer within the air channel is essential in accurately modeling the overall heat transmission through the roof assembly. The AtticSim computer tool was validated against the steep-slope attic assembly with direct-nailed asphalt shingle. The model predicted well the surface temperature of the shingles, the attic air temperature, and, as a result, the heat flow penetrating into the conditioned space. Efforts are continuing to modify the code for predicting the effects of the airflow occurring on the underside of tile and stone-coated metal roofs. Correlations by McAdams (1954), Brinkworth (2000), and simple boundary layer theory for a constant solar flux are predicting reasonable heat transfer measures within the inclined air channel. The measures of airflow determined from the tracer gas experiments match well the backcalculated values deduced from the correlations provided by McAdams (1954), Brinkworth (2000), and simple boundary layer theory correlations. We therefore have good representative airflow measures for sub-tile venting and are in good position to implement an algorithm fashioned after the work by Brinkworth (2000) for use in AtticSim to predict thermal performance of roofs with underside venting. Once validated, we recommend the code be used for predicting ceiling heat fluxes in the demonstration homes in California. 


\section{NOMENCLATURE}

\begin{tabular}{|c|c|c|c|}
\hline$\delta_{\mathrm{t}}$ & \multirow{2}{*}{$\begin{array}{l}\text { thermal boundary layer thickness ( } \mathrm{ft} \text { ) } \\
\text { thermal emittance }\end{array}$} & $\delta$ & momentum boundary layer (ft) \\
\hline$\varepsilon$ or $\mathrm{E}$ & & $\mathrm{P}$ & wetted perimeter of channel (ft) \\
\hline o or SR & solar reflectance & $\dot{\mathrm{m}}$ & mass flow rate $(\mathrm{lbm} / \mathrm{hr})$ \\
\hline $\mathrm{L}$ & length from soffitt to roof ridge (ft) & $\mathrm{C}_{\mathrm{P}}$ & specific heat $\left(\mathrm{Btu} / \mathrm{lbm} \cdot{ }^{\circ} \mathrm{R}\right)$ \\
\hline $\mathrm{T}$ & temperature $\left({ }^{\circ} \mathrm{F}\right)$ & $\alpha$ & thermal diffusivity $\left(\mathrm{ft}^{2} / \mathrm{s}\right)$ \\
\hline$\hbar$ & convective coefficient $\left(\mathrm{Btu} / \mathrm{hr} \cdot \mathrm{ft}^{2} \cdot{ }^{\circ} \mathrm{F}\right)$ & $\begin{array}{l}\mathrm{CDD}_{65} \\
\mathrm{HDD}_{65}\end{array}$ & cooling and heating degree-days ${ }^{1}$ \\
\hline $\mathrm{C}$ & concentration of $\mathrm{CO}_{2}$ (ppmv) & Subscripts & \\
\hline $\mathrm{V}$ & volume of inclined channel & wall & underside of Tile Roof \\
\hline$\dot{\mathrm{V}}$ & volumetric flow rate (cfm) & IR & infrared spectrum \\
\hline$\beta$ & coefficient of Thermal Expansion $\left(1 /{ }^{\circ} \mathrm{F}\right)$ & $\mathrm{i}$ & initial value \\
\hline $\mathrm{g}$ & gravity $\left(32.2 \mathrm{ft} / \mathrm{s}^{2}\right)$ & solar & irradiance \\
\hline$q^{\prime \prime}$ & Heat flux $\left(\mathrm{Btu} / \mathrm{hr} \cdot \mathrm{ft}^{2}\right)$ & $\mathrm{x}$ & $\mathrm{x}$-distance from soffitt to ridge \\
\hline$\theta$ & Roof slope & $\mathrm{y}$ & y-distance normal to roof deck \\
\hline$v$ & kinematic viscosity $\left(\mathrm{ft}^{2} / \mathrm{s}\right)$ & roof & tile roof surface or underside \\
\hline $\mathrm{k}$ & thermal conductivity $\left(\mathrm{Btu} / \mathrm{hr} \cdot \mathrm{ft} \cdot{ }^{\circ} \mathrm{F}\right)$ & $\infty$ & outdoor ambient \\
\hline$\eta$ & $=\mathrm{y} / \delta_{\mathrm{t}}$ & $\mathrm{t}$ & time \\
\hline $\mathrm{U}(\mathrm{x}, \mathrm{y})$ & velocity (ft/sec) & channel & $\begin{array}{l}\text { inclined air gap made by tile and } \\
\text { roof deck }\end{array}$ \\
\hline$\overline{\mathrm{NU}}$ & Average Nusselt number $\left(\frac{\hbar \mathrm{L}}{\mathrm{k}_{\text {air }}}\right)$ & air & air within inclined channel \\
\hline $\operatorname{Pr}$ & $\begin{array}{l}\text { Prandtl numberError! Objects cannot } \\
\text { be created from editing field codes. }\end{array}$ & air out & air entering soffitt \\
\hline $\mathrm{Ra}$ & \multirow{2}{*}{ Rayleigh number $=\left(\frac{g \beta(\Delta T) L^{3}}{v \cdot \alpha}\right)$} & air in & air leaving ridge \\
\hline & & & \\
\hline $\mathrm{Ra}^{*}$ & Modified Rayleigh number $=\left(\frac{g \beta q^{\prime \prime} L^{4}}{k \cdot v \cdot \alpha}\right)$ & & \\
\hline
\end{tabular}

\footnotetext{
${ }^{1}$ A degree-day is the difference between the average daily temperature and the base temperature of $65^{\circ} \mathrm{F}$.
} 


\section{REFERENCES}

Akbari, H., R. Levinson, P. Berdahl. 2004a. "A Review of Methods for the Manufacture of Residential Roofing Materials.” Lawrence Berkeley National Laboratory Report LBNL-55574, Berkeley, CA.

Akbari, H., P. Berdahl, R. Levinson, R. Wiel, A. Desjarlais, W. Miller, N. Jenkins, A. Rosenfeld, C. Scruton. 2004b. "Cool Colored Materials for Roofs." Proceedings of the 2004 ACEEE Summer Study on Energy Efficiency in Buildings, Vol. 1, p. 1, Pacific Grove, CA.

Arnold, J. N., I. Catton, D. K. Edwards. 1976. "Experimental Investigation of Natural Convection in Inclined Rectangular Regions of Differing Aspect Ratios." Journal of Heat Transfer. February, 67-71.

ASTM. 2000. Designation E741-00: Standard Test Method for Determining Air Change in a Single Zone by Means of a Tracer Gas Dilution. American Society for Testing and Materials, West Conshohocken, $\mathrm{Pa}$.

ASTM. 1997. Designation C 1371-97: Standard Test Method for Determination of Emittance of Materials Near Room Temperature Using Portable Emissometers. American Society for Testing and Materials, West Conshohocken, Pa.

ASTM. 1996. Designation E903-96: Standard Test Method for Solar Absorption, Reflectance, and Transmittance of Materials Using Integrating Spheres. American Society for Testing and Materials, West Conshohocken, $\mathrm{Pa}$.

Beal, D. and S. Chandra. 1995. "The Measured Summer Performance of Tile Roof Systems and Attic Ventilation Strategies in Hot Humid Climates." Thermal Performance of the Exterior Envelopes of Buildings VI, U.S. DOE/ORNL/BETEC, Dec. 4-8, Clearwater, Fla.

Bejan A. 1984. Convection Heat Transfer. John Wiley and Sons, New York.

Brinkworth, B. J. 2000. "A Procedure for the Routine Calculation of Laminar Free and Mixed Convection in Inclined Ducts.” International Journal of Heat and Fluid Flow 21, 456-462.

Burch, D. M. and Treado, S. J. 1979. "Ventilating Residences and Their Attics for Energy Conservation-An Experimental Study." NBS Special Publication 548: Summer Attic and Whole House Ventilation. National Bureau of Standards, Washington, D.C.

FHA. 1942 (rev). Property Standards and Minimum Construction Requirements for Dwellings. Federal Housing Administration, Washington, D.C.

Hollands, K. G. T., T. E. Unny, G. D. Raithby, and L. Konicek. 1976. "Free Convection Heat Transfer Across Inclined Air Layers. ” Journal of Heat Transfer, May, 189-193.

Kehrer, M. 2005. “Ventilated versus Compact Roof.” THERMAL PERFORMANCE. 76-108.

Kollie, T. G., F. J. Weaver, D. L. McElroy. 1990. "Evaluation of a Commercial, Portable, AmbientTemperature Emissometer.” Rev. Sci. Instrum., Vol. 61, 1509-1517.

Kusuda, T. 1969. "Thermal Response Factors for Multi-Layer Structures of Various Heat Conduction Systems," ASHRAE Transactions, Vol. 75, Part 1, 246-271. 
Lagus, P. L., V. Kluge, P. Woods, and J. Pearson. 1988. "Tracer Gas Testing within the Palo Verde Nuclear Generating Station Unit 3 Auxiliary Building." Proceedings of the $20^{\text {th }}$ NRC/DOE Air Cleaning Conference. Boston, August.

Levinson, R., H. Akbari, and J. Reilly. 2004. "Cooler Tile-Roofed Buildings with Near-Infrared Reflective Nonwhite Coatings.” Lawrence Berkeley National Laboratory Report LBNL-54902, Berkeley, CA.

Levinson R., P. Berdahl, and H. Akbari. 2005a. "Solar spectral optical properties of pigments, Part I: model for deriving scattering and absorption coefficients from transmittance and reflectance measurements." Solar Energy Materials \& Solar Cells, Vol 89/4 pp 319-349.

- 2005b. "Solar spectral optical properties of pigments, Part II: survey of common colorants." Solar Energy Materials \& Solar Cells, Vol 89/4 pp 351-389.

McAdams, W. H. 1954. Heat Transmission. $3^{\text {rd }}$ ed., McGraw-Hill, New York.

Miller W. A., K. T. Loyle, A. O. Desjarlais, H. Akbari, R. Levenson, P. Berdahl, S. Kriner, S. Weil, and R. G. Scichili. 2004. "Special IR Reflective Pigments Make a Dark Roof Reflect Almost Like a White Roof." Thermal Performance of the Exterior Envelopes of Buildings, IX. Proceedings of ASHRAE THERM IX, Clearwater, Fla., December.

Miller, W.A., M. D. Cheng, S. Pfiffner, and N. Byars. 2002. "The Field Performance of High-Reflectance Single-Ply Membranes Exposed to Three Years of Weathering in Various U.S. Climates." Final Report to SPRI, Inc., August.

Ozsunar, A., Baskaya, S., and Sivrioglu, M. 2001. "Numerical Analysis of Grashof Number, Reynolds Number and Inclination Effects on Mixed Convection Heat Transfer in Rectangular Enclosures." International Communications in Heat and Mass Transfer, 28, No. 7, September.

Parker, D. S., P. W. Fairey, and L. Gu. 1991. "A Stratified Air Model for Simulation of Attic Thermal Performance." Insulation Materials: Testing and Applications, 2nd Volume, ASTM STP 1116, R. S. Graves and D. C. Wysocki, Eds., 44-69, American Society for Testing and Materials, Philadelphia.

Parker, D. S., J. K. Sonne, and J. R. Sherwin. 2002. "Comparative Evaluation of the Impact of Roofing Systems on Residential Cooling Energy Demand in Florida." ACEEE Summer Study on Energy Efficiency in Buildings. Proceedings of American Council for an Energy Efficient Economy, Pacific Grove, Calif, August.

Peavy, B. A. 1979. "A Model for Predicting the Thermal Performance of Ventilated Attics." Summer Attic and Whole House Ventilation, NBS Special Publication 548, Washington, D.C.

Petrie, T. W., A. O. Desjarlais, R. H. Robertson, and D .S. Parker. 2000. "Comparison of Techniques for In-situ, Non-damaging Measurement of Solar Reflectance of Low-slope Roof Membranes." Presented at the $14^{\text {th }}$ Symposium on Thermophysical Properties. Submitted to International Journal of Thermophysics, National Institute of Standards and Technology, Boulder, Colo.

Petrie, T. W., T. K. Stovall, K. E. Wilkes, and A. O. Desjarlais. 2004. "Comparison of Cathedralized Attics to Conventional Attics: Where and When Do Cathedralized Attics Save Energy and Operating Costs?" Presented at ASHRAE THERM VIII, Clearwater, Fla., December. To be published in Thermal Performance of the Exterior Envelopes of Buildings, IX. 
Romero, M. I., and Brenner, R. J. 1998. "Instrumentation and Measurement of Airflow and Temperature in Attics Fitted with Ridge and Soffitt Vents." ASHRAE Transactions 104.

Rose, W. B. 1995. "The History of Attic Ventilation Regulation and Research." Thermal Performance of the Exterior Envelopes of Buildings VI. American Society of Heating, Refrigeration and Air-Conditioning Engineers, Atlanta.

Walker, I. S. 1993. "Prediction of Ventilation, Heat Transfer and Moisture Transport in Attics." Ph.D. dissertation, Edmonton, Alberta, Canada.

Wilkes, K. E. 1991.Thermal Model of Attic Systems with Radiant Barriers. ORNL/CON-262, Oak Ridge National Laboratory, Oak Ridge, Tenn. 


\section{Appendix A}
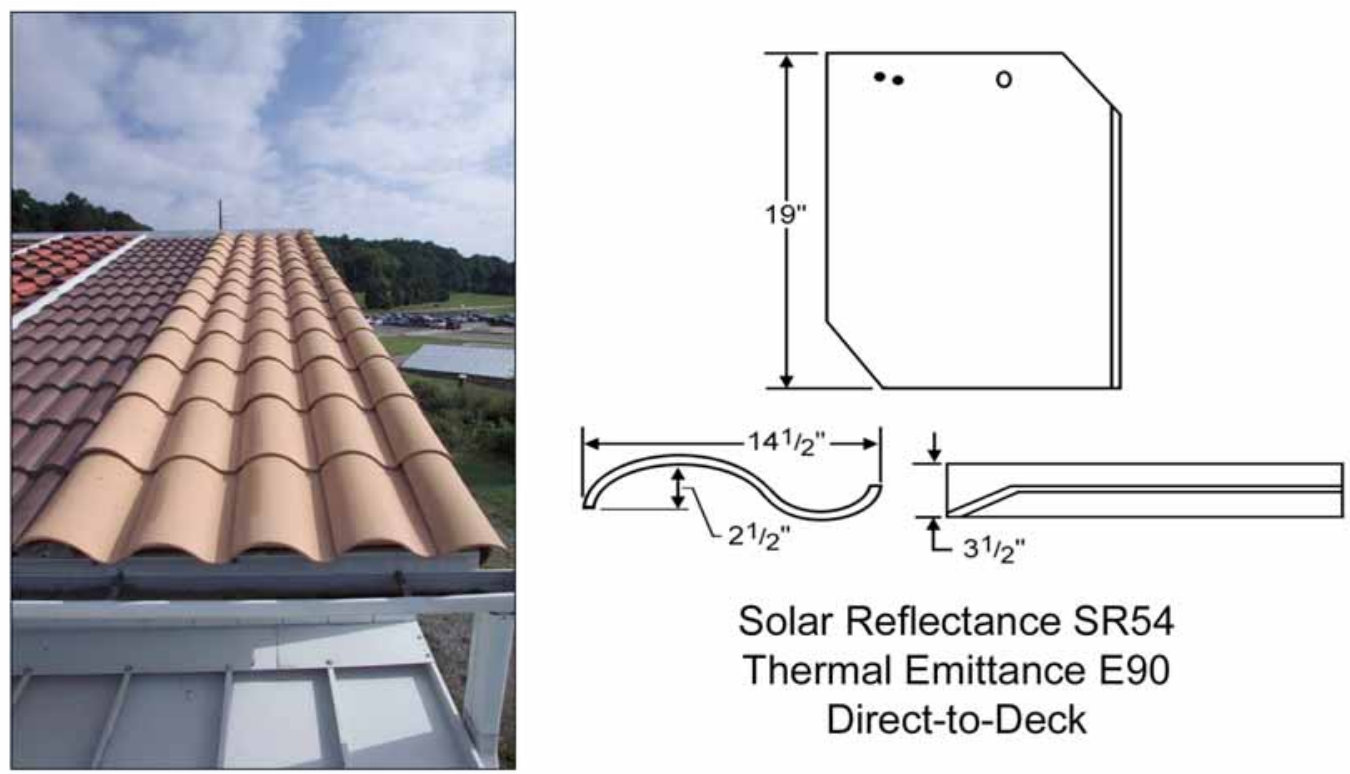

Solar Reflectance SR54

Thermal Emittance E90

Direct-to-Deck

S-Mission clay tile field-tested on the ESRA at the campus of the Buildings Technology Center.
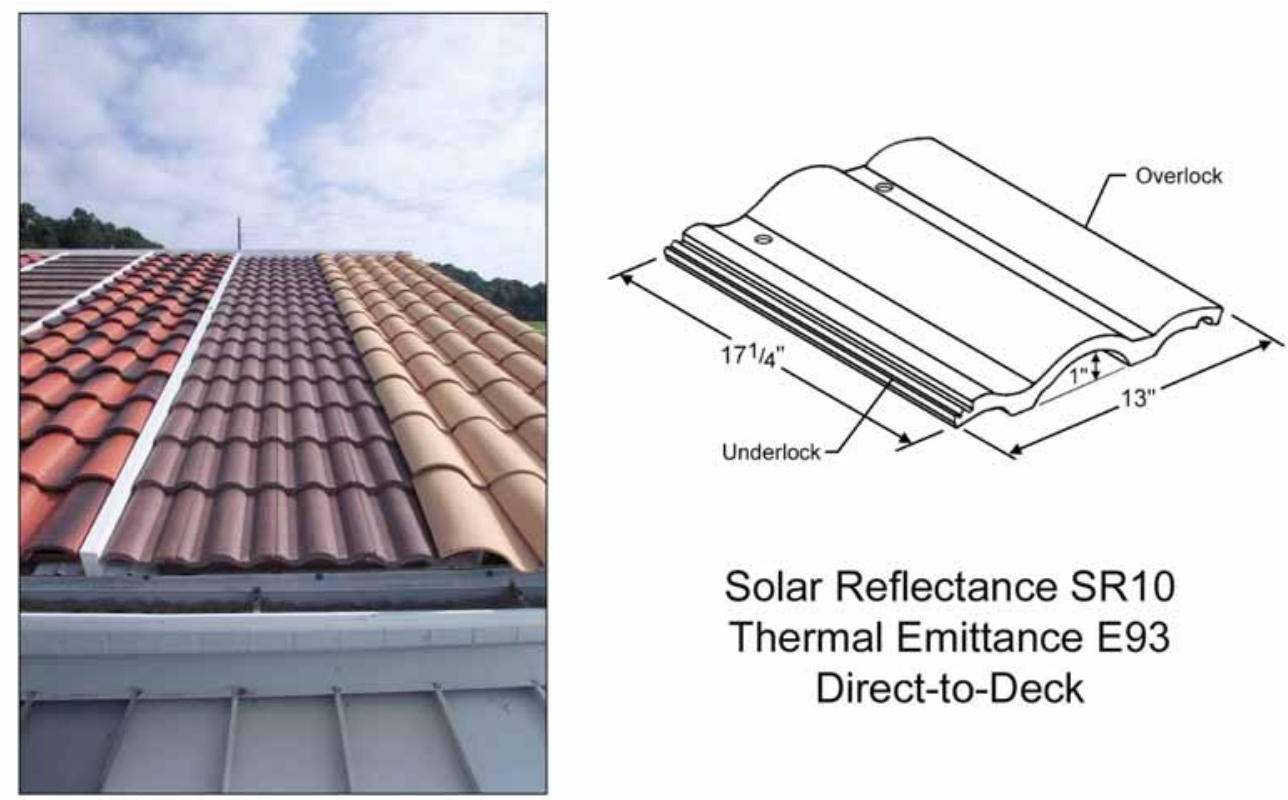

Solar Reflectance SR10

Thermal Emittance E93

Direct-to-Deck

Medium-profile concrete tile used at the Fair Oaks, Calif., demonstrations and also at ORNL. 

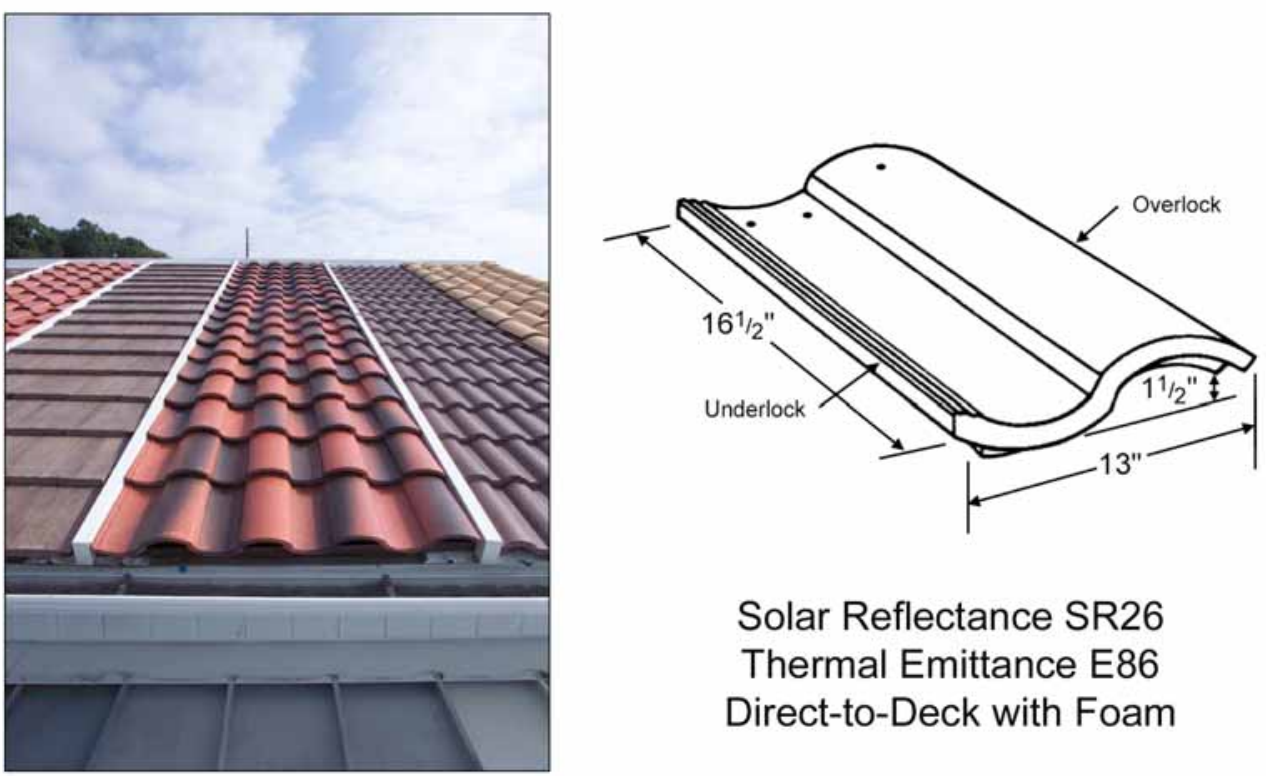

Solar Reflectance SR26 Thermal Emittance E86 Direct-to-Deck with Foam

S-Mission concrete tile spot adhered with foam.
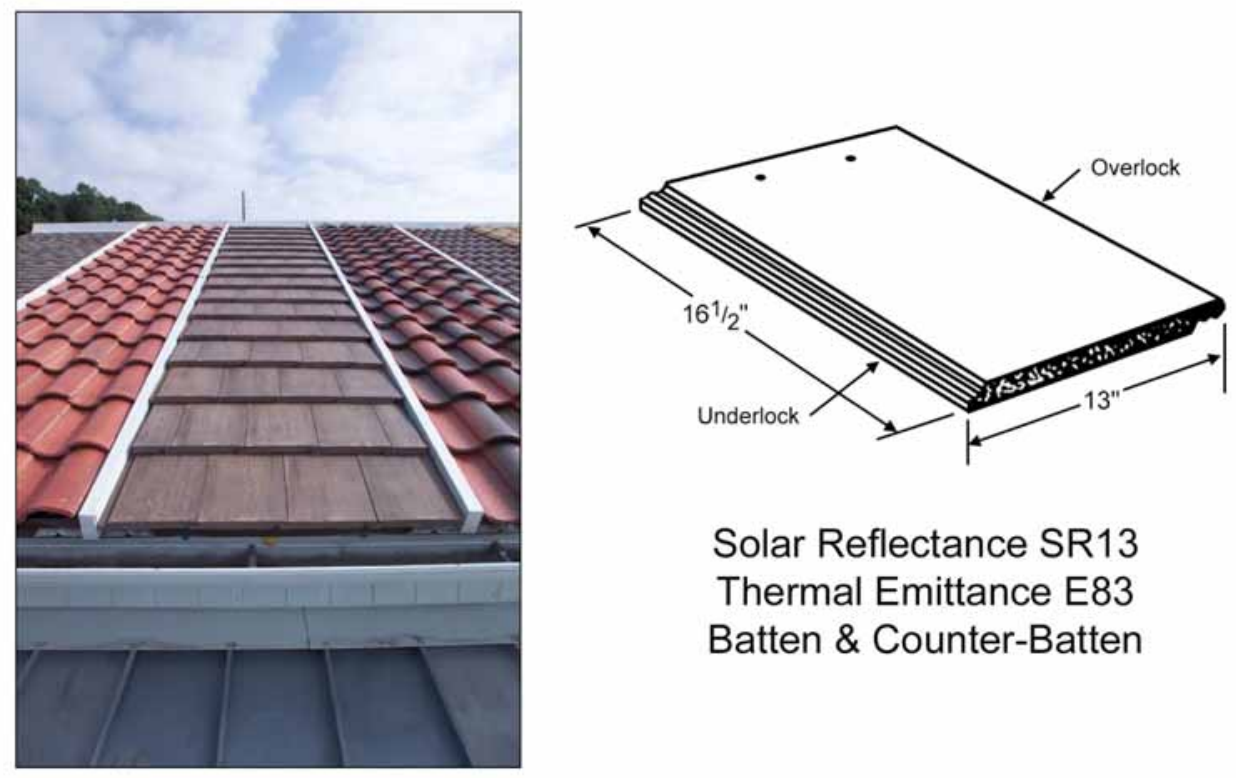

Solar Reflectance SR13

Thermal Emittance E83

Batten \& Counter-Batten

Concrete slate tile having solar reflectance and thermal emittance close to that of the asphalt shingle roof. 

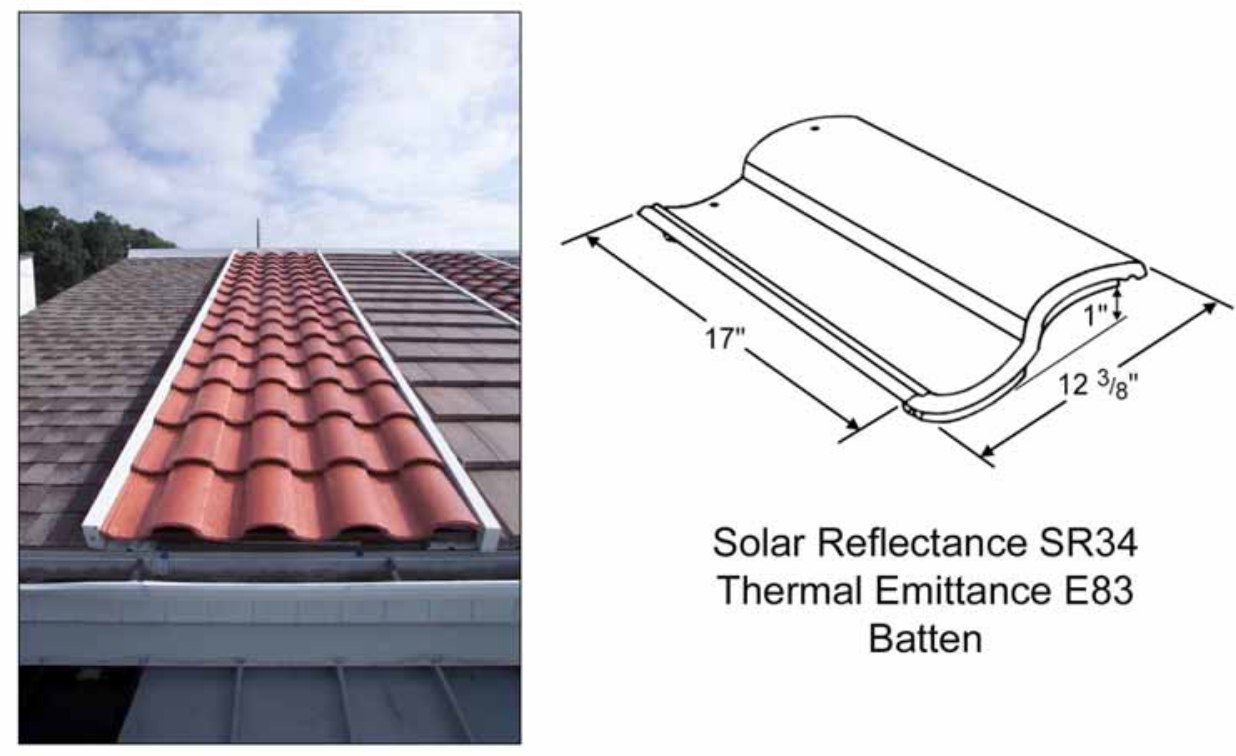

Solar Reflectance SR34

Thermal Emittance E83

Batten

S-Mission Tile Roof attached with battens running parallel to the ridge of the roof. 



\section{Appendix B}

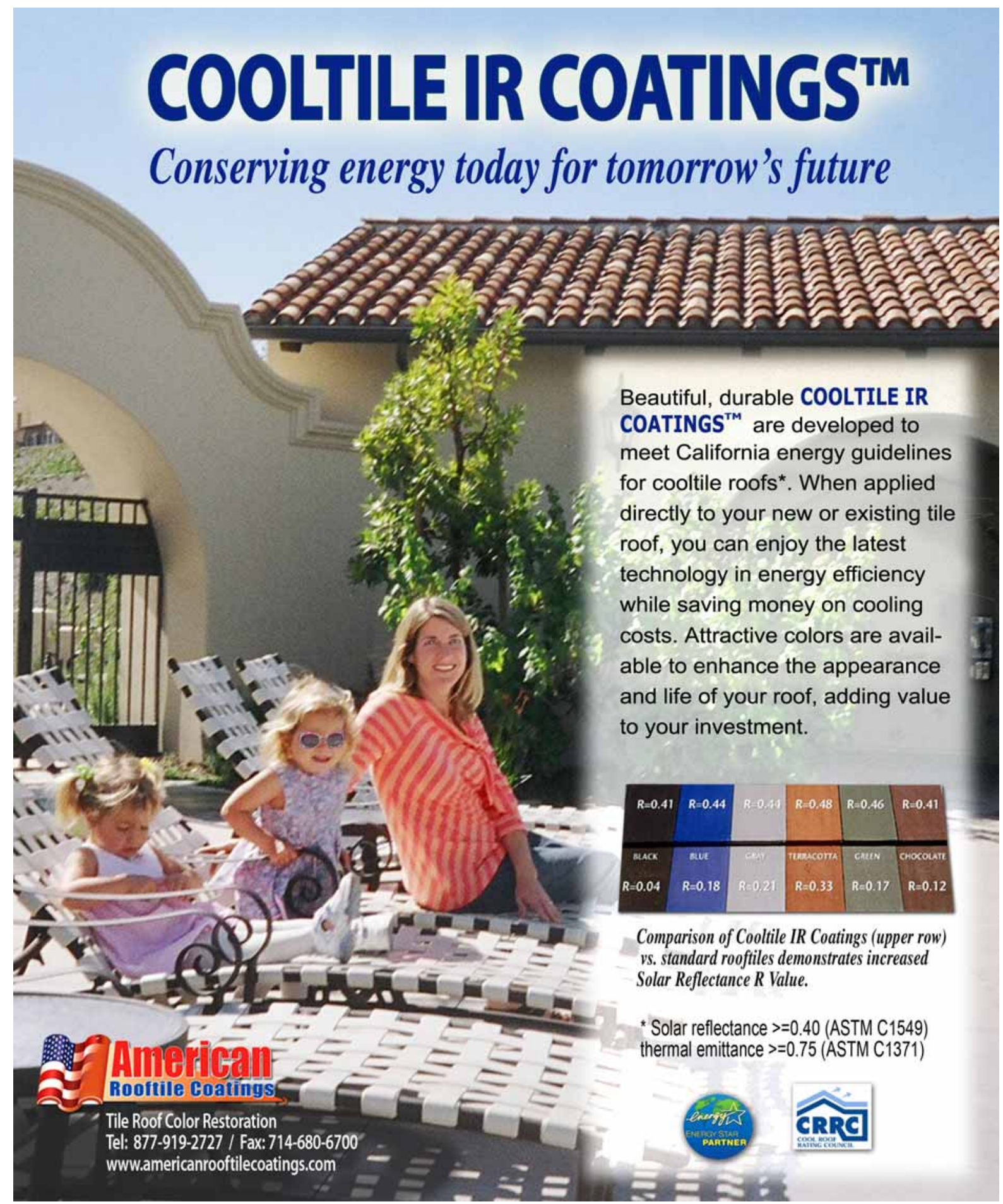


